\title{
Host genetic variability and pneumococcal disease: a systematic review and meta- analysis
}

\author{
Anne T. Kloek, Matthijs C. Brouwer and Diederik van de Beek* (1)
}

\begin{abstract}
Background: Pneumonia, sepsis, meningitis, and empyema due to Streptococcus pneumoniae is a major cause of morbidity and mortality. We provide a systemic overview of genetic variants associated with susceptibility, phenotype and outcome of community acquired pneumococcal pneumonia (CAP) and invasive pneumococcal disease (IPD).

Methods: We searched PubMed for studies on the influence of host genetics on susceptibility, phenotype, and outcome of CAP and IPD between Jan 1, 1983 and Jul 4, 2018. We listed methodological characteristics and when genetic data was available we calculated effect sizes. We used fixed or random effect models to calculate pooled effect sizes in the meta-analysis.

Results: We identified 1219 studies of which 60 studies involving 15,358 patients were included. Twenty-five studies (42\%) focused on susceptibility, 8 (13\%) on outcome, 1 (2\%) on disease phenotype, and 26 (43\%) on multiple categories. We identified five studies with a hypothesis free approach of which one resulted in one genome wide significant association in a gene coding for lincRNA with pneumococcal disease susceptibility. We performed 17 meta-analyses of which two susceptibility polymorphisms had a significant overall effect size: variant alleles of MBL2 (odds ratio [OR] 1.67, 95\% confidence interval [Cl] 1.04-2.69) and a variant in CD14 (OR 1.77, 95\% Cl 1.18-2.66) and none of the outcome polymorphisms.

Conclusions: Studies have identified several host genetics factors influencing risk of pneumococcal disease, but many result in non-reproducible findings due to methodological limitations. Uniform case definitions and pooling of data is necessary to obtain more robust findings.
\end{abstract}

Keywords: Host genetic variability, Pneumococcal disease, Systematic review, Meta-analysis

\section{Background}

Pneumococcal infection is a major cause of morbidity and mortality worldwide [1]. Invasive pneumococcal disease (IPD) is an infection confirmed by the isolation of Streptococcus pneumoniae from a normally sterile site, while non-invasive pneumococcal disease includes sinusitis, mastoiditis, acute otitis media, and communityacquired pneumonia (CAP). Streptococcus pneumoniae has been identified as the most common cause of CAP in adults [2-4]. In 2015, an estimated 515.000 deaths (range 302.000-609.000) were attributed to pneumococcal

\footnotetext{
* Correspondence: d.vandebeek@amc.nl

Department of Neurology, Amsterdam Neuroscience, Amsterdam UMC, University of Amsterdam, Meibergdreef, Amsterdam, The Netherlands
}

infection among children less than 5 years of age globally [5]. The incidence of IPD is strongly age-related, with the highest incidence in younger children and the elderly with incidence ranging from 11 to 27 per 100,000 in Europe [6-8]. Mortality rates for IPD vary from 12 to $22 \%$ in adults in the western world and are substantially higher in low income countries [7-11].

Pneumonia with empyema and/or bacteraemia, meningitis, and bacteraemia are the commonest manifestations of IPD. [12] Identified risk factors for IPD include splenectomy, cancer, and diabetes mellitus, but in a substantial proportion of patients no risk factor can be identified [7]. Extreme phenotype studies in patients with recurrent or familial IPD first identified genetic risk factors to increase

(c) The Author(s). 2019 Open Access This article is distributed under the terms of the Creative Commons Attribution 4.0 International License (http://creativecommons.org/licenses/by/4.0/), which permits unrestricted use, distribution, and 
susceptibility [13]. Most of the identified genetic variation was found in genes controlling the host response to microbes [14]. Subsequently several case-control and cohort studies described genetic variation to increase susceptibility and to predict unfavourable outcome of pneumococcal disease and disease phenotype $[6,9,15]$.

In the past 20 years several genetic association studies investigated host genetics in relation to susceptibility and outcome of pneumococcal disease, sometimes showing conflicting results. Here we systematically review these studies, perform a meta-analysis and discuss the potential of these findings for understanding the pathophysiological mechanisms of pneumococcal disease.

\section{Methods}

\section{Systematic review}

We performed a systematic review and meta-analysis with the objective to summarize host genetic variation associated with susceptibility, phenotype or outcome of patients with IPD and CAP. The following search terms were used in PubMed: ((Streptococcus pneumoniae) OR (S. pneumoniae) OR pneumococcal OR pneumococcus) AND (polymorphisms OR polymorphism OR (genetic variant) $\mathrm{OR}$ (genetic variants) OR (genetic association study) OR (single nucleotide polymorphism) OR (single nucleotide polymorphisms) OR SNP OR SNPs OR genotype OR genotypes) without language restrictions and with search date cut offs between Jan 1, 1983 and Jul 4, 2018. We identified additional publications by checking the references in those published studies and via communicating with experts in the field. Extreme phenotype, review studies, and studies with specific patients groups like immunocompromised patients were excluded. Studies were eligible for inclusion if the population of interest was reported with at least one of the outcome measures.

\section{Meta-analysis and statistical analyses}

Each study was scored for methodological quality, such as study design, definition of the investigated condition, ethnicity of included patients, sample size, selection of the control group, quality control of genotyping, statistical methods and correction for multiple testing. We performed meta-analyses for multiple studies that assessed a single genetic polymorphism (or a combination of polymorphisms) of which genotype data was available in the manuscript. Different nomenclatures of genetic variants included in the review can be found in Additional file 1: Table S1. Review Manager 5.3 was used to generate Forest plots and calculate overall effect sizes with a fixed effects model or random effects model if the results between studies were too heterogeneous ( $Q$ test for homogeneity $p<0.05)[16]$. The funder of the study had no role in study design, data collection, data analysis, data interpretation, or writing of the report. The corresponding author had full access to all the data in the study and had final responsibility for the decision to submit for publication.

\section{Results}

\section{Systematic review}

The date of search was 4 July 2018 and yielded 1219 articles (Fig. 1 - flow diagram) of which 60 articles were eventually included in the review [17-76]. Studies were published from 2000 to 2018 and contained 16,034 patients included in 27 different cohorts from 15 countries. There was a substantial overlap of cohorts and patients between the published articles. Of all studies, 24 (40\%) analysed the influence of genetic variation on susceptibility to pneumococcal disease, $8(13 \%)$ on outcome, 2 (3\%) on disease phenotype, and 26 (43\%) studies assessed multiple categories of which 24 (40\%) on susceptibility and outcome (Tables 1 and 2). Eight studies (13\%) focused on patients with pneumococcal CAP, 49 studies (82\%) on patients with IPD and 3 studies (5\%) on IPD and pneumococcal CAP.

Twenty-eight studies (47\%) were performed in adults (8188 patients) and 15 studies (25\%) in children (4988 patients), 13 (22\%) in all age categories (2675 patients) and 4 studies (7\%) did not specify the age range of included patients. The population was limited to white patients in 39 studies (64\%), mixed ethnicity in 9 studies (15\%), and African origin in 3 studies (5\%); ethnicity was not specified in 9 studies (15\%). The sample size was less than 100 patients in 17 studies (28\%), 100-500 patients in 40 studies (67\%), and more than 500 in 3 studies (5\%). The study population was defined by positive cultures of blood, cerebrospinal fluid or joint fluid in 41 studies (68\%), and in 2 studies (3\%) cultures of sputum or tracheal aspirate were included as well. Other studies used PCR, antigen tests or both (14 studies, 23\%) to confirm bacterial presence. The control populations of the 57 susceptibility cohorts varied considerably and included healthy population-based controls, blood donors, participants in vaccine programs, patients from other hospital departments, university personnel or proxies and family members of patients. Some studies did specify if controls were ethnically, age or sex matched (32 cohorts, $56 \%$ ).

Most studies (92\%) had a candidate genetic variant approach looking at a selection of single nucleotide polymorphisms (range 1 to 326 polymorphisms; median 4). Five studies had a hypothesis free approach, including 1 genome wide association study, 2 exome wide association studies, and 2 sequencing studies [63, 69-72]. Most studies $(41 ; 68 \%)$ determined genotypes by PCR followed by various methods of allelic discrimination, of 


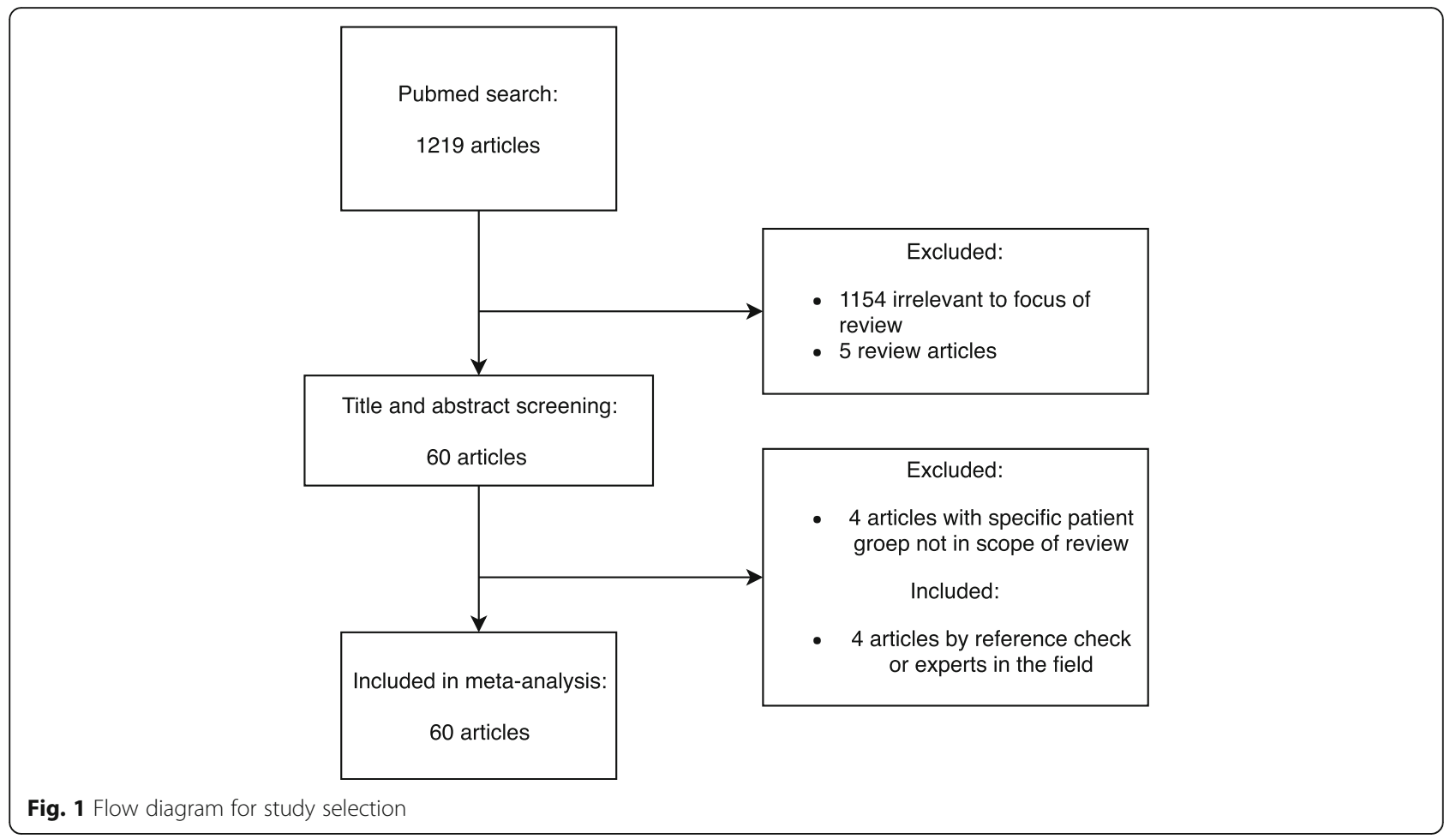

which 18 studies confirmed genotypes with sequencing, 3 studies with retesting of samples and 19 studies did not mention if or how genotypes were confirmed. Eleven studies $(18 \%)$ used real time PCR (by Taqman genotyping assays), 1 (2\%) PCR with mass spectrometry analysis, and 7 (12\%) next generation sequencing (12\%) for determination of genotypes. Seven studies (12\%) described blinding of laboratory personnel for the clinical information.

The $x^{2}$ test and/or Fisher's exact test was used in 48 studies (80\%) to compare genotypes of selected groups. Logistic regression with correction for confounders to compare genotype frequencies between selected groups was done in 31 studies (52\%). Correction for multiple testing was used in $23(66 \%)$ of the 35 studies that assessed three or more polymorphisms.

\section{Meta-analysis}

Meta-analysis could be done for 16 (combinations of) polymorphisms assessing an association with susceptibility and for 1 combination of polymorphisms assessing an association with outcome of pneumococcal disease. The number of cohorts in the meta-analysis varied between 2 and 10. Significant heterogeneity was found in 8 studies included in the meta-analyses for which therefore a random-effects model was used. Forest plots were made and overall ORs with 95\% CIs were calculated (Additional file 2).

\section{Candidate gene approach}

\section{Pathogen recognition receptor signalling pathways}

Toll-like receptors (TLRs) or nod-like receptors (NRLs) are pathogen recognition receptors of the innate immune system that recognize molecular patterns derived from microbes. [77] Fourteen studies assessed the effect of polymorphisms in 11 genes of the TLR and NLR signalling pathways on pneumococcal disease $[29,30,33$, $43,50,53,57,59,63,65,67,72,74,76]$. Six polymorphisms were assessed in multiple studies and could be included in a meta-analysis. Five studies assessed the association between polymorphisms in TLR2 (rs5743708) and TLR4 (rs4986790) and susceptibility [30, 33, 50, 59, 74]. In the meta-analyses neither of the polymorphisms showed any effect. Rs352140 in TLR9 was assessed in two studies for an association with susceptibility which resulted in no association in the separate studies and the meta-analysis [43, 74]. The CD14 CC genotype of rs2569190 was significantly associated with susceptibility in a meta-analysis including two studies (OR 1.77, 95\% CI 1.18-2.66) [33, 59]. Two studies including 224 patients and 284 controls studied rs4251513 of IRAK4 and no effect was found on susceptibility in the metaanalysis $[63,65]$.

Polymorphisms in the Toll interleukin-1 receptor domain-containing adaptor protein (TIRAP) gene were investigated in three studies including five cohorts with in total 1601 white patients and 2826 African patients [29, $67,76]$. In the meta-analysis with the polymorphism 


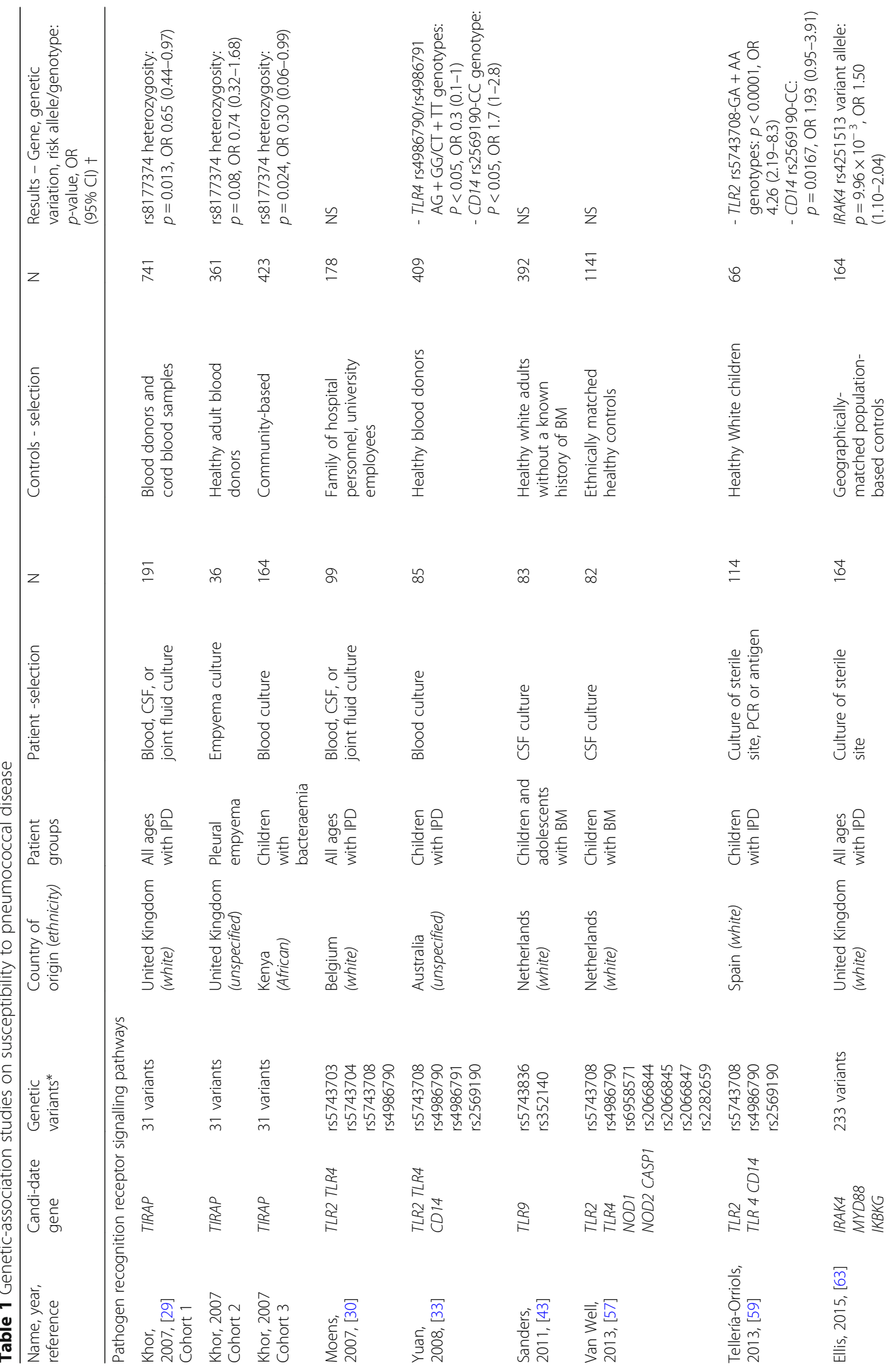




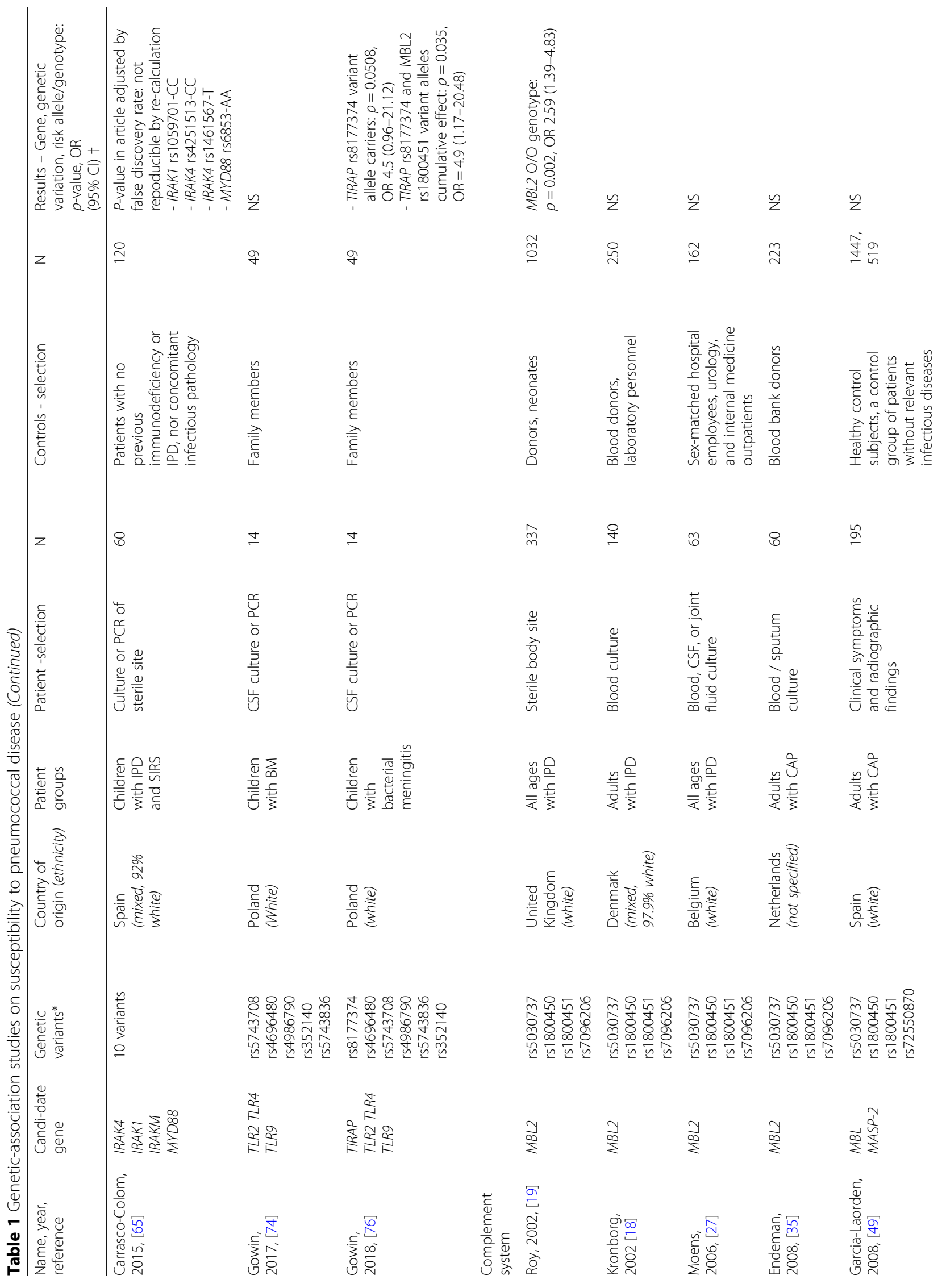




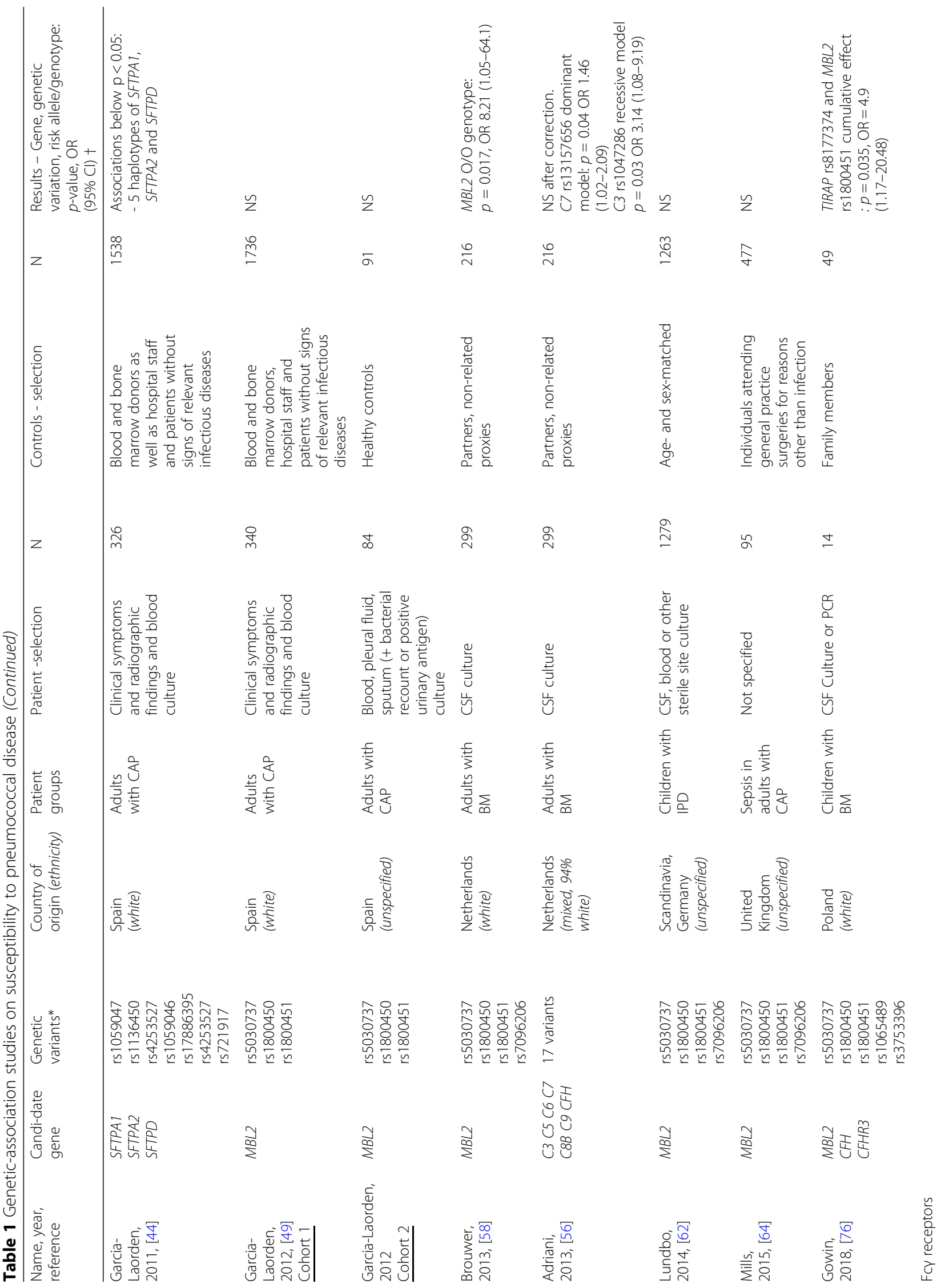




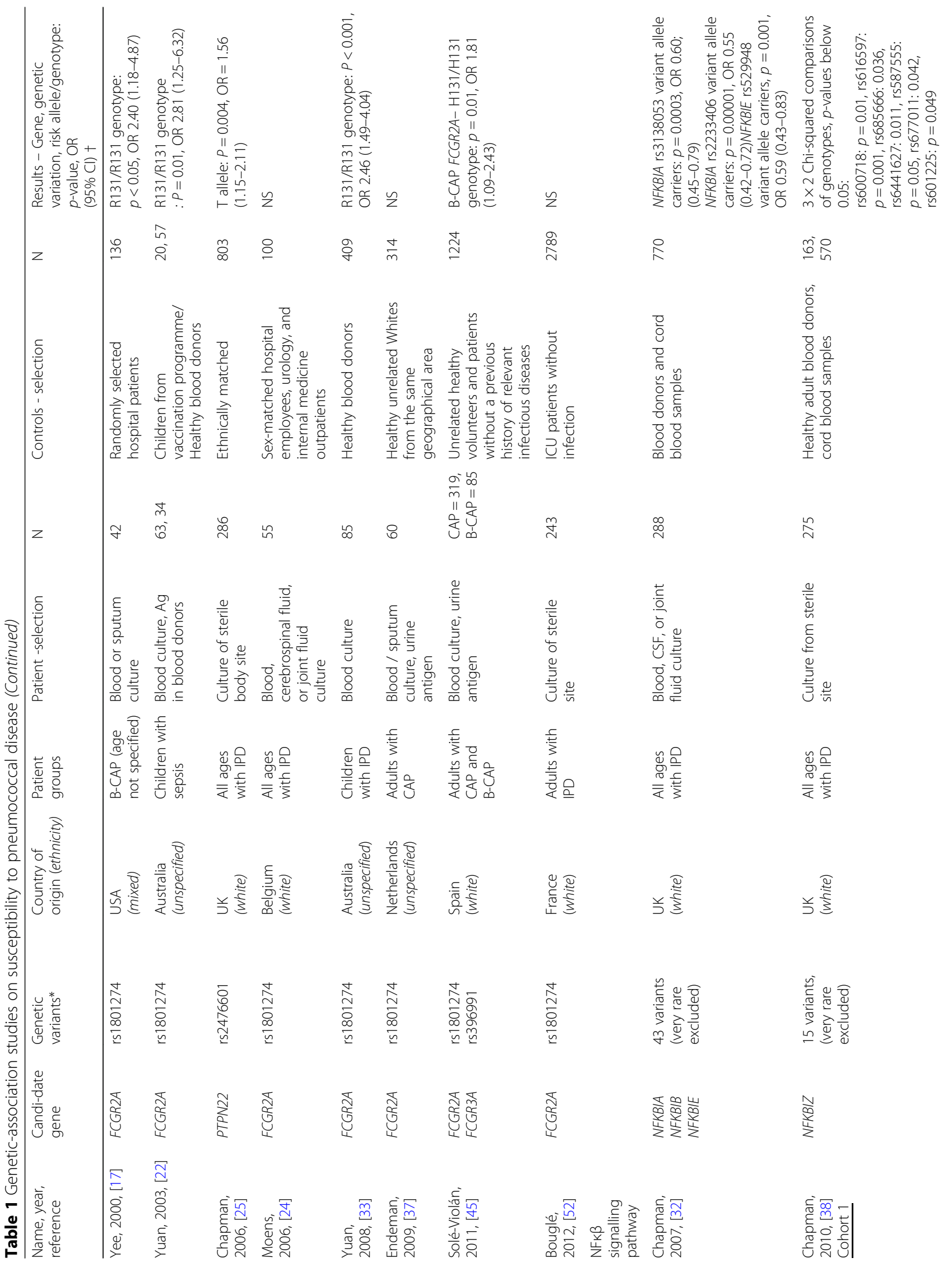




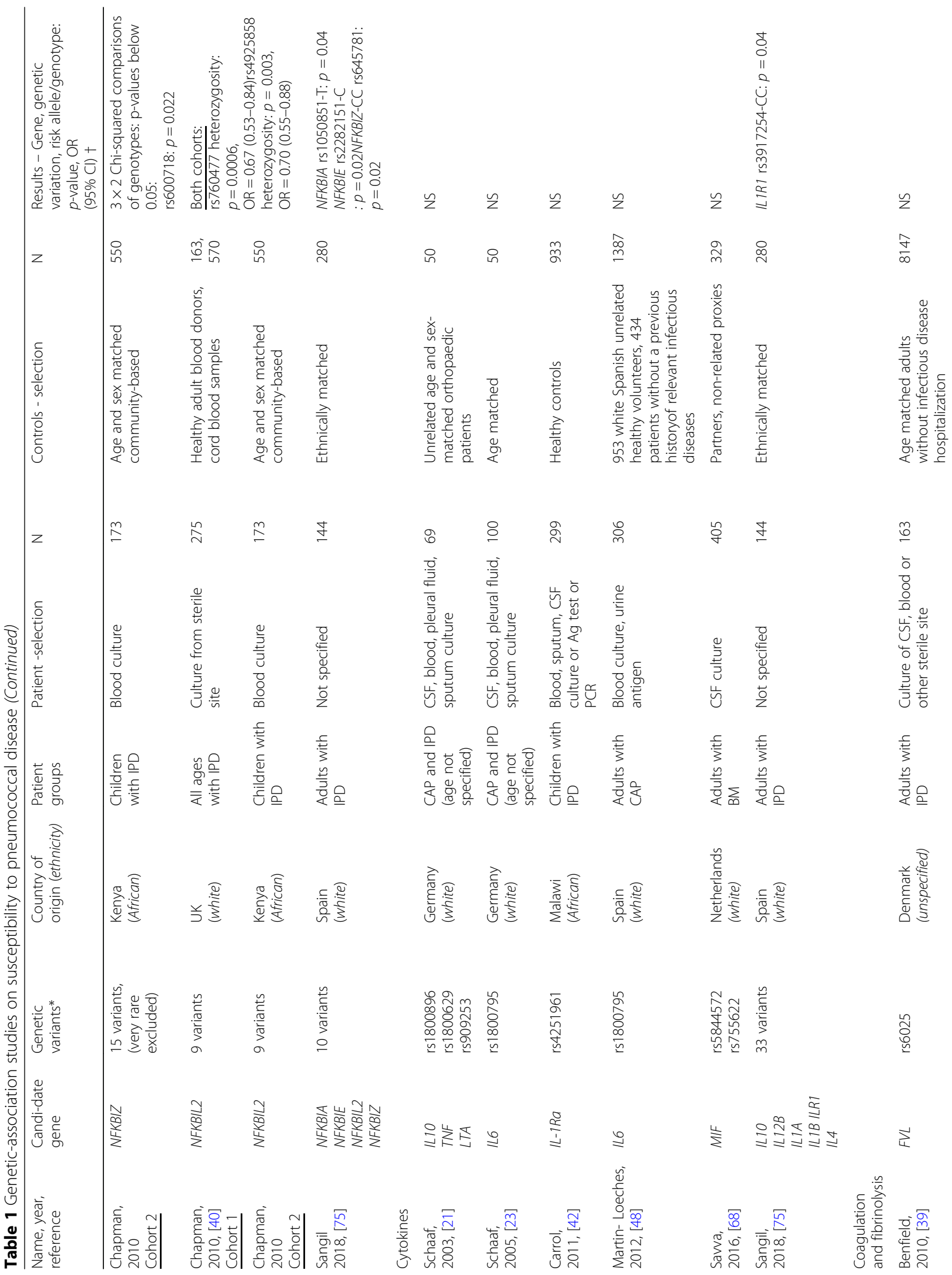




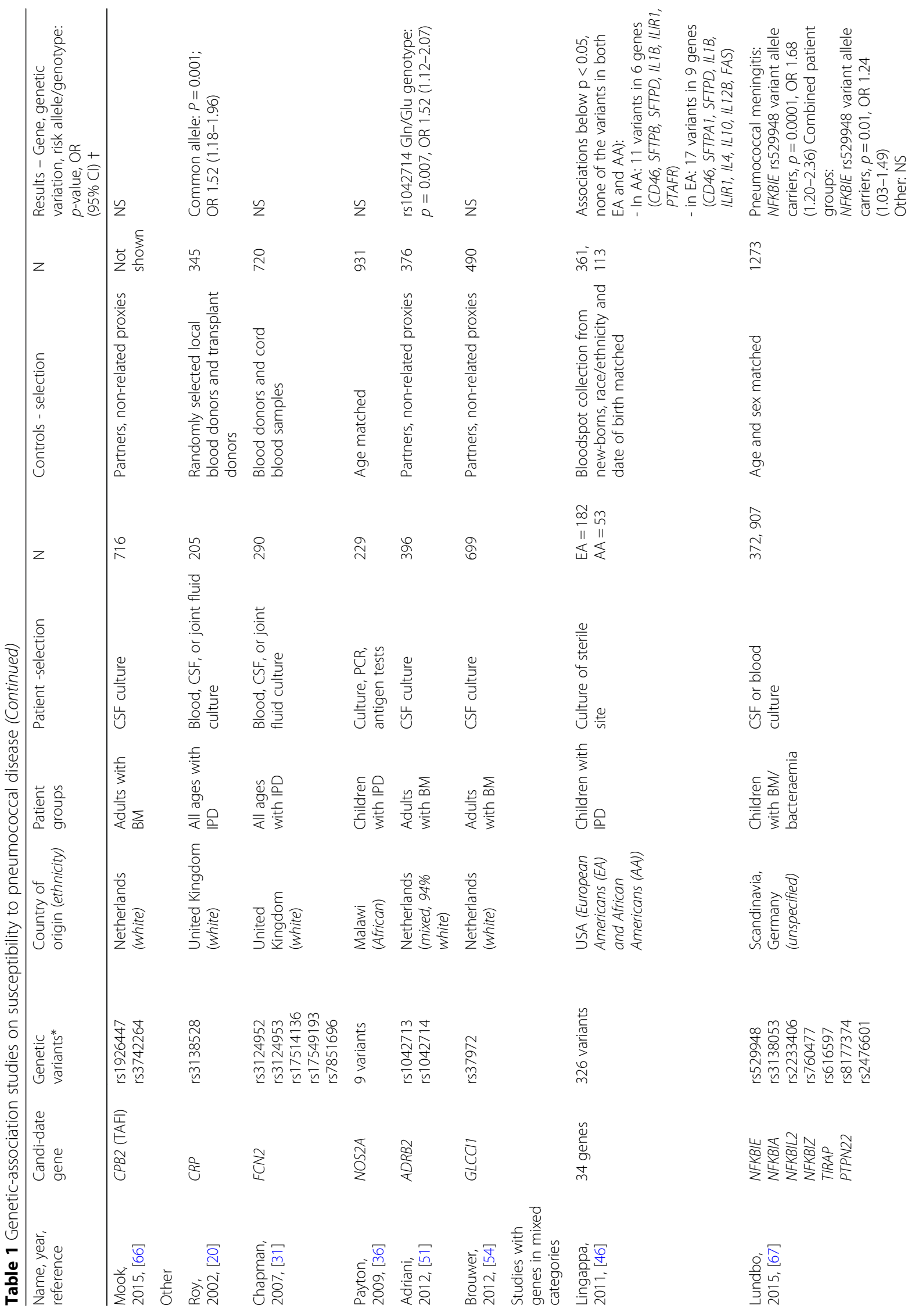




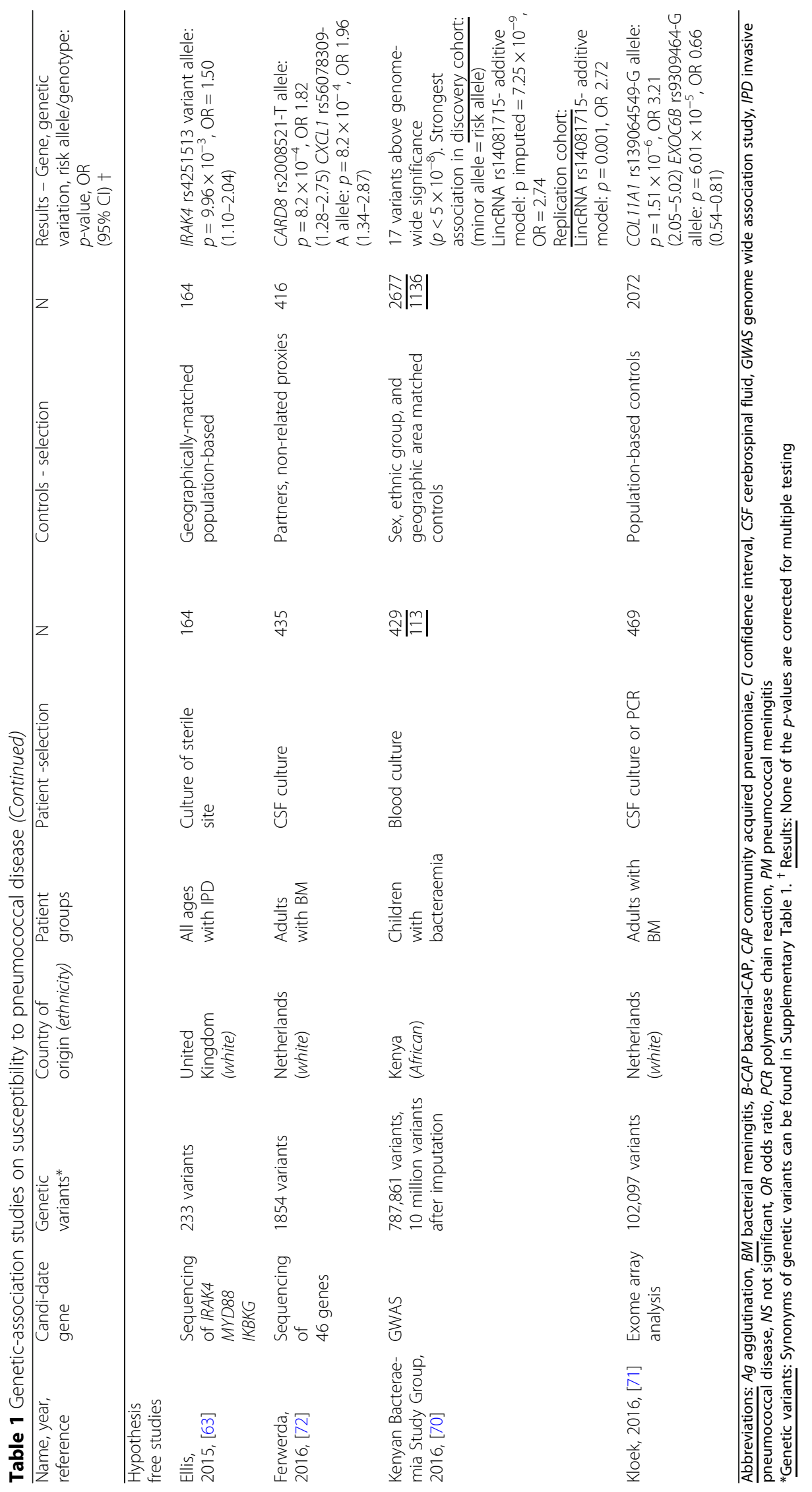




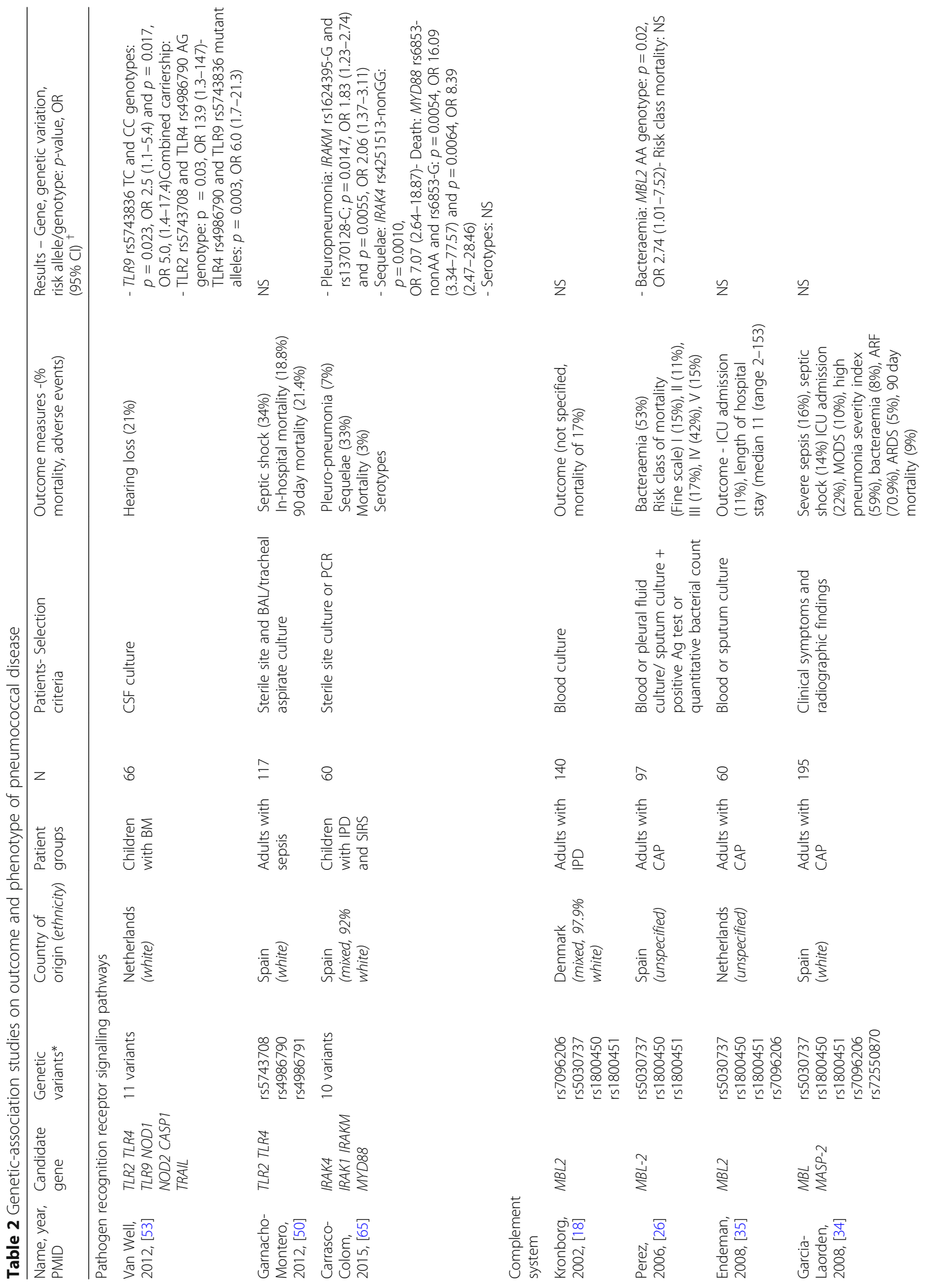




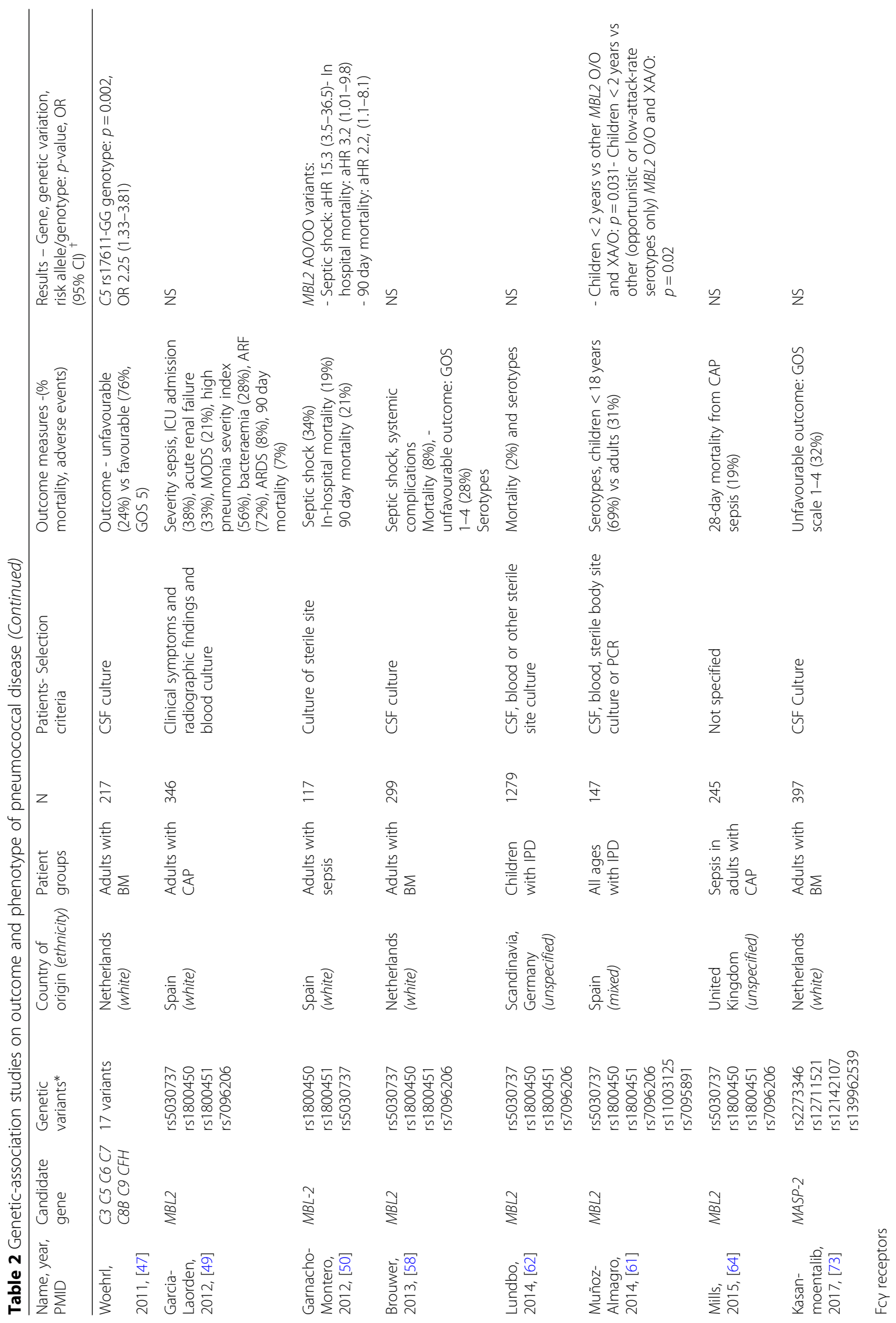




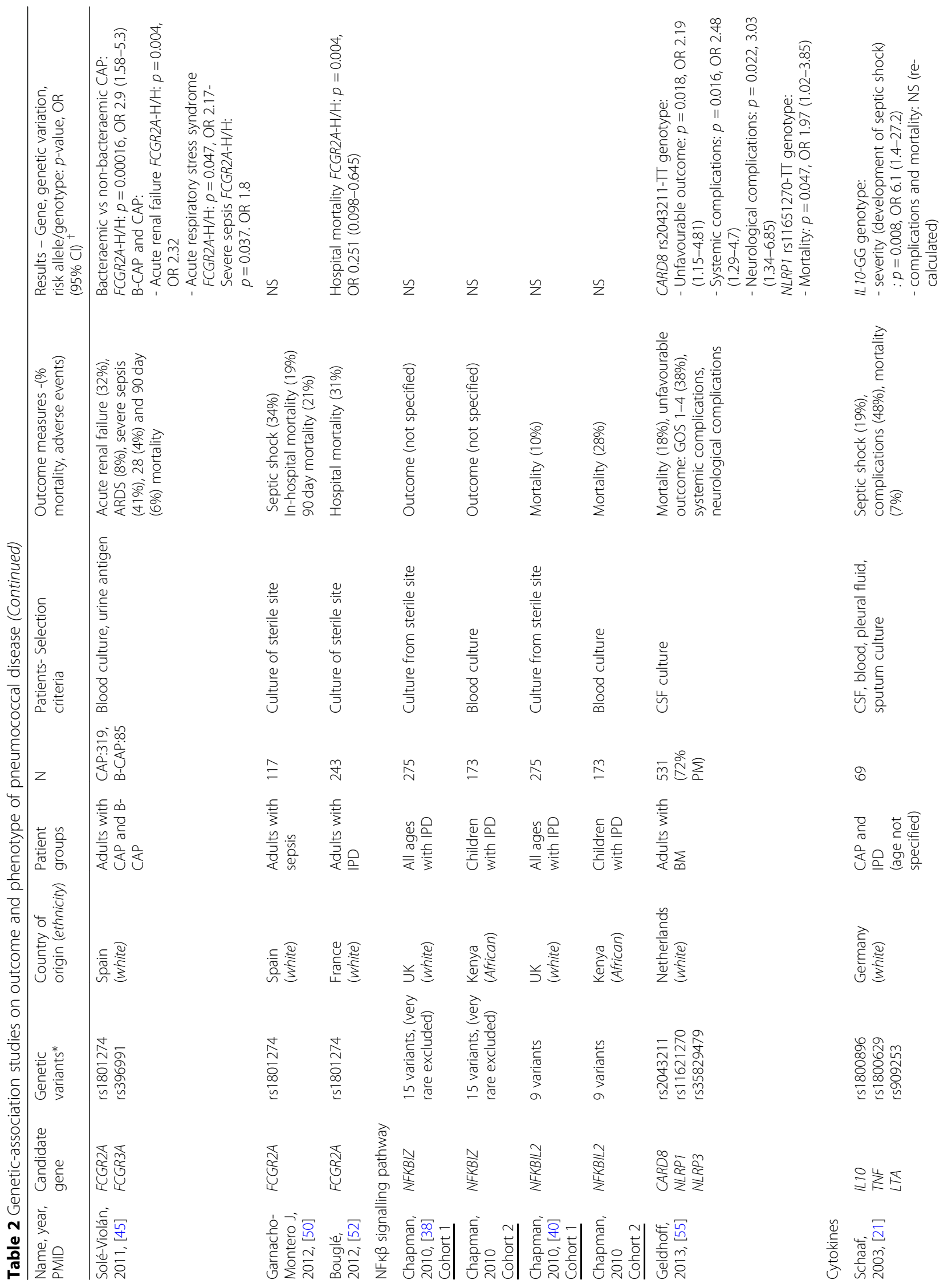




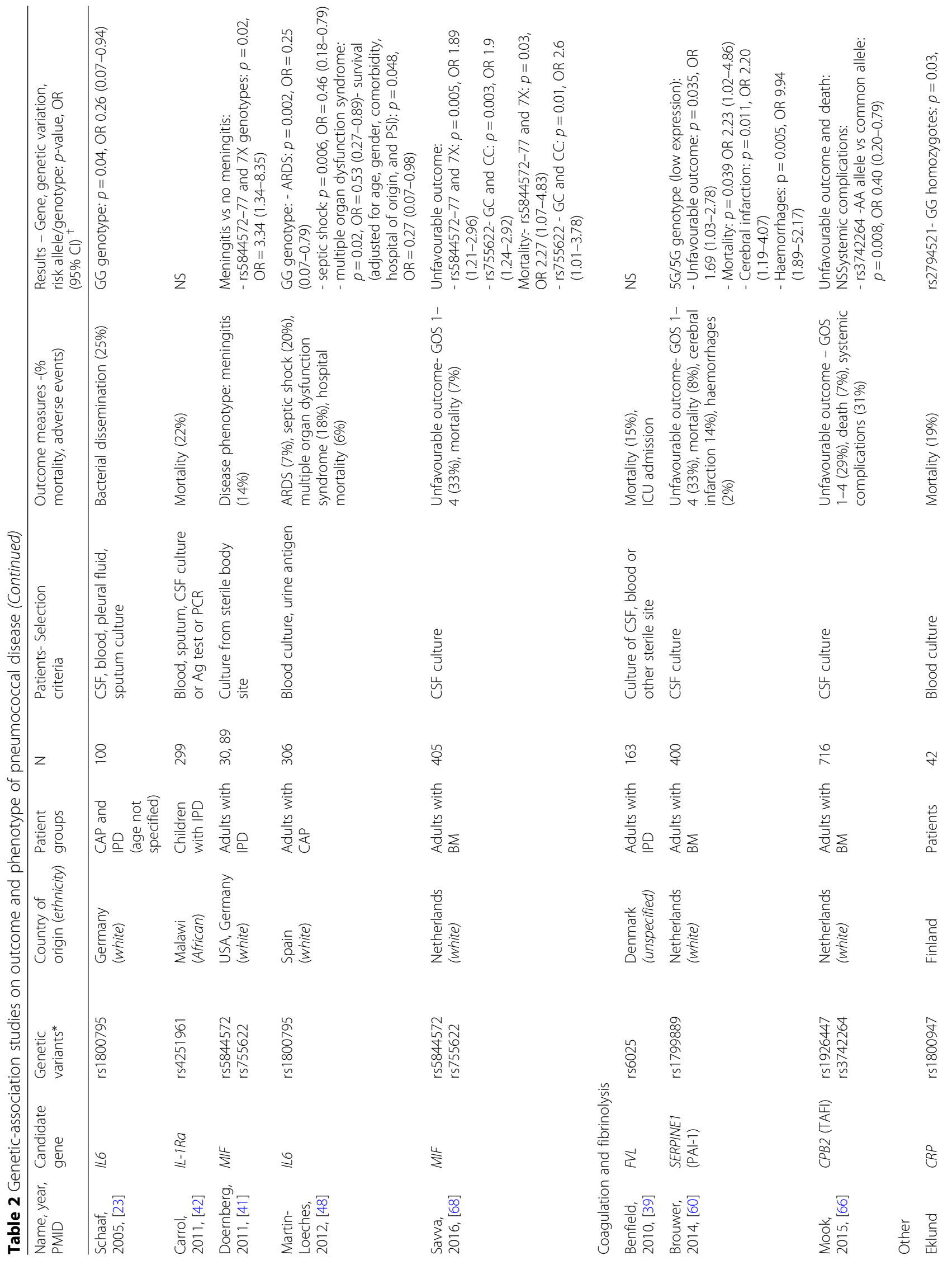




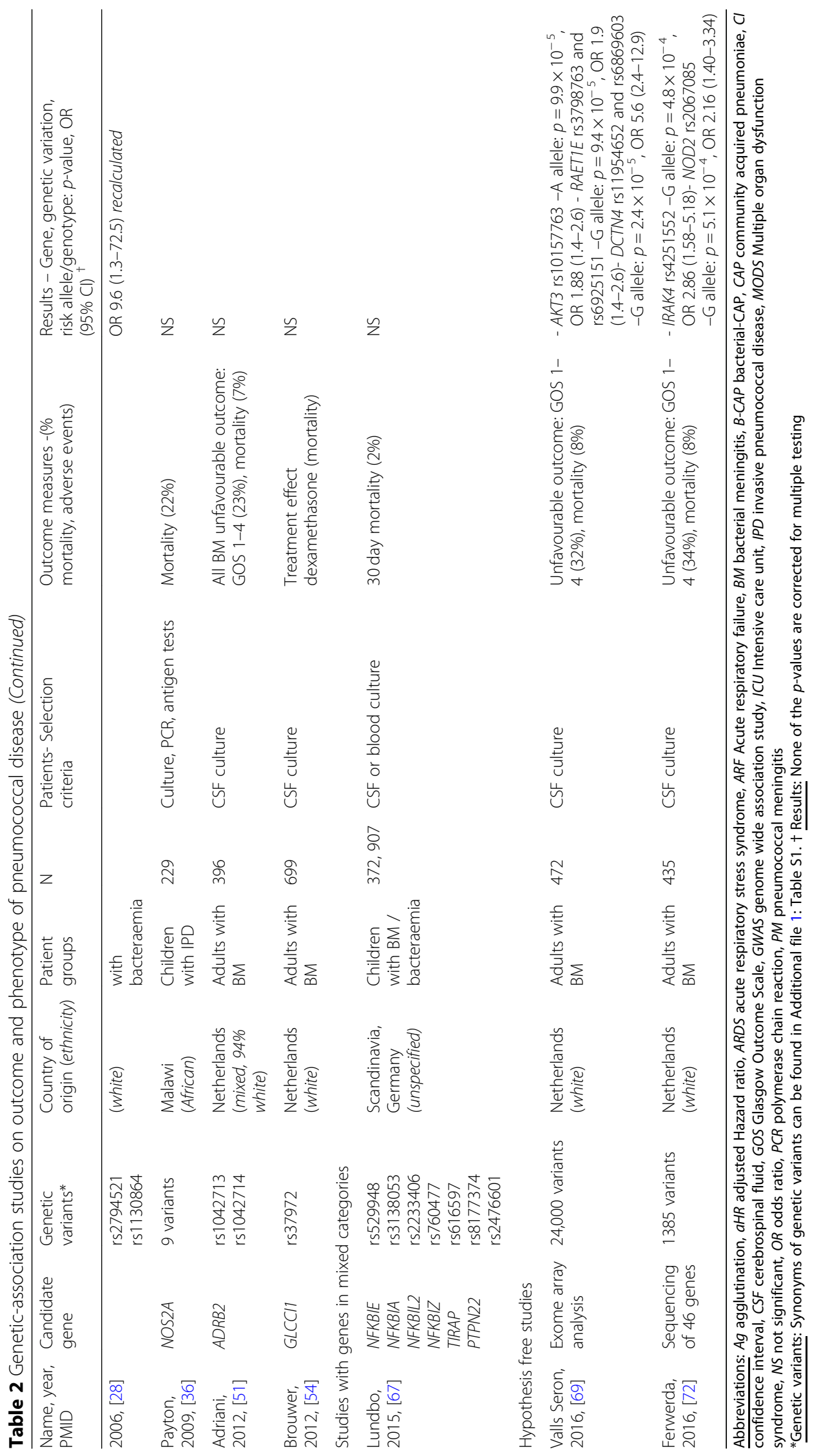


rs8177374 was not associated with pneumococcal disease.

Three studies assessed the effect on outcome of polymorphisms in genes involved in pathogen recognition receptor signaling $[50,53,65]$. A Spanish study with 60 patients assessed the effect of 10 polymorphisms in IRAK4, IRAK1, IRAKM and MYD88 on outcome of pneumococcal disease, but after re-calculation of their results the patients groups appeared too small to find significant assocations [65]. A study of 66 children with pneumococcal meningitis on the influence of NOD1, NOD2, TLR2, TLR4, TLR9, TRAIL and CASP1 polymorphisms on susceptibility and outcome showed no significant associations after correction for multiple testing [53]' [57].

\section{Complement system}

Mannose-binding lectin (MBL) is a soluble pattern recognition receptor of the collectin group that activates the lectin complement pathway after binding to a microorganism. Structural mutations in exon 1 of the $M B L 2$ gene resulting in variant allele B, C or D (rs1800450, rs1800451 or rs5030737), have been associated with reduced functional serum MBL levels [78].

The effect of $M B L 2$ variant allele $\mathrm{B}, \mathrm{C}$ or $\mathrm{D}$ on susceptibility to pneumococcal disease was assessed in 9 studies which were included in the meta-analysis $[18,19,27$,
$35,49,58,62,64,76]$. In the meta-analysis, 2504 patients and 4749 controls were included, and homozygosity of any of the variant alleles was significantly associated with susceptibility to pneumococcal disease (OR 1.67, 95\% CI 1.04-2.69). A Funnel plot with the 10 study cohorts showed the overall effect on susceptibility was likely influenced by publication bias (Fig. 2). Effect on outcome of $M B L 2$ variant allele $\mathrm{B}, \mathrm{C}$ or $\mathrm{D}$ was assessed in 10 studies, but only 3 of these studies could be included in the meta-analysis due to lacking of detailed genotypic data in the manuscripts $[35,58,64]$. The meta-analysis showed no significant effect on outcome of pneumococcal disease. Rs7096206 in the promotor region of $M B L 2$ was analysed in seven studies and yielded no significant association with susceptibility in the metaanalysis [18, 19, 27, 35, 49, 58, 62].

After binding of MBL to a pathogens surface, a serine protease called MASP (MBL-associated serine protease) is activated, which cleaves complement precursors to activated complement proteins further down the cascade [79]. Associations of polymorphisms in MASP2 with pneumococcal disease were assessed in two studies, but showed no significant effect on outcome and susceptibility [34, 73].

Surfactant protein A or D (SFTPA, SFTPD) are also collectins and act as a first line of defence against microorganisms in the nasopharynx and respiratory tract by facilitating elimination of microorganisms [80]. A study

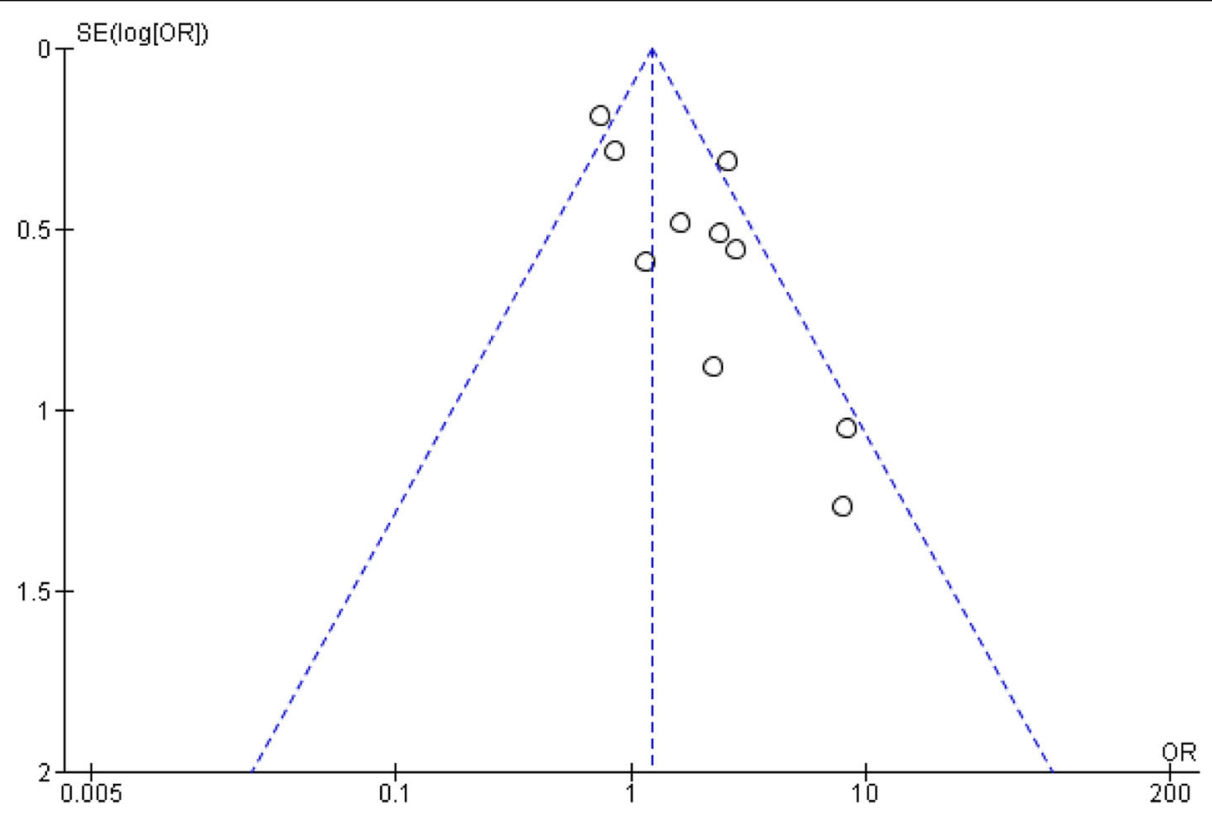

Fig. 2 Funnel plot with MBL2 studies. Funnel plot with studies assessing the effect of MBL2 variant allele B, C or D (rs1800450, rs1800451 or rs5030737) on pneumococcal disease susceptibility. Each dot represents one study. The vertical blue dashed line corresponds to the mean effect size on susceptibility. The outer dashed lines indicate the triangular region within which 95\% of studies are expected to lie. SE: standard error as the measure of study size with a reversed scale (most powerful studies are placed towards the top), OR: odds ratio as the effect size of the studies on a log scale 
of 7 SFTPD and SFTPA polymorphisms in 326 pneumococcal CAP patients and 1538 controls showed no association of these genes with susceptibility [44]. Another study of 182 European Americans (EA) and 53 African Americans (AA) with IPD assessed the effect on susceptibility of 24 polymorphisms in SFTPA and SFTPD [46]. Because genotypic data was not provided they could not be included in the meta-analysis. Their strongest associations were with two SFTPD polymorphisms (rs17886286 and rs12219080; OR 0.45, 95\% CI 0.250.82and OR 0.32, 95\% CI 0.13-0.78), not corrected for multiple testing [46].

L-Ficolin (encoded by FCN2) is a pattern-recognition molecule, that enhances phagocytosis and activates the lectin pathway of complement activation after binding to lipoteichoic acid or Gram-positive bacteria [81]. Five functional polymorphisms in FCN2 were analysed in 290 patients with pneumococcal disease and in 720 controls yielding no associations with susceptibility [31].

After initiation of the three complement activation pathways the final common pathway is activated, in which C5 is converted into C5a,an important anaphylatoxin and a chemoattractant [82]. A Dutch study with 217 pneumococcal meningitis patients assessed the effect on outcome of 17 polymorphisms in 7 complement components further down the cascade [47]. This yielded 1 significant association of rs17611 in C5 with unfavourable outcome (OR 2.25, 95\% CI 1.33-3.81) after correction for multiple testing [47]. Another Dutch study investigated in the same population the effect of these complement components on susceptibility showing no significant associations after correction for multiple testing [56].

\section{Fcy receptors}

Fc (fragment crystallizable) receptors are found on the surface of immune cells and bind to immunoglobulins (Ig). Of the 6 types of Fcy receptors, FcyRIIa and FcyRIIIa exists as two allotypic variants with different binding affinity for IgG [83]. The more common F158 allotype of the FCGR3A gene has a lower IgG affinity than the V158 allotype (rs396991) [84]. For the FCGR2A gene the more common H131 allotype has a higher IgG affinity than the R131 allotype (rs1801274) [84]. Seven studies assessed the effect of rs1801274 (FCGR2A) on susceptibility and 3 assessed the effect on outcome of pneumococcal disease [17, 22, 24, 33, 37, 45, 50, 52]. The outcome studies lacked genotypic data for the metaanalysis and one study on susceptibility was excluded, because patient overlap with another study $[22,33]$. In the meta-analysis on susceptibility 6 studies with a total of 570 patients and 4972 controls were included and no overall effect was found [17, 24, 33, 37, 45, 52]. One study assessed the effect of rs396991 (FCGR3A) in 85 bacteraemia pneumococcal pneumonia patients and 1224 healthy controls, showing no effect on susceptibility and outcome [45].

\section{$N F K \beta$ signalling pathway}

NFkB (nuclear factor kappa-light-chain-enhancer of activated $B$ cells) is a transcriptional regulator important for both the adaptive and innate immune response [85]. Six studies investigated the effect of polymorphisms in genes coding for modulators of the NFKB signalling pathway on outcome and susceptibility of pneumococcal disease [32, 38, 40, 55, 67, 75]. Five polymorphisms in genes coding for NFKB inhibitors could be analysed in a metaanalysis. The effect of polymorphisms in NFKBIA and NFKBIE (rs3138053, rs2233406, rs529948) on susceptibility was assessed in two studies, revealing no significant associations in the meta-analyses [32, 67]. Two other polymorphisms in the $\mathrm{NFKB}$ inhibitor genes NFKBIZ (rs616597) and NFKBIL2 (rs760477) were assessed in 3 cohorts for an effect on susceptibility and meta-analysis showed no significant associations [38, 40, 67]. A study including 531 adult pneumococcal meningitis patients and 376 controls studied two polymorphisms in CARD8 and NLRP1 both coding for proteins required for activation of $\mathrm{NF \kappa B}$ or caspases in the context for inflammation or apoptosis respectively [85]. This study showed an association of rs2043211 in CARD8 with poor outcome (OR $2 \cdot 10,95 \%$ CI 1.04-4.21) and rs11651270 in NLRP1 with death (OR 2.32, 95\% CI 1.12-4.78), but this was not significant after correction for multiple testing [55].

\section{Cytokines}

Cytokines are important molecules mediating cell signalling and include small proteins like chemokines, interferons, interleukins (ILs), lymphokines, or tumor necrosis factors (TNFs) [86, 87] Seven studies assessed the effect of polymorphisms in 11 cytokine genes on susceptibility, disease phenotype and outcome of pneumococcal disease $[21,23,41,42,48,68,75]$. The polymorphism rs1800795 in IL6 was assessed in two studies, showing no effect on susceptibility in the meta-analysis [23, 48]. One Spanish study with 144 IPD patients and 280 controls assessed the effect on susceptibility of 33 polymorphisms in the genes coding for IL-10, IL-12B, IL-1A, IL-1B, IL-R1 and IL-4 [75]. None were significantly associated after correction for multiple testing [75].

Macrophage migrating inhibitory factor (MIF) is a pro-inflammatory cytokine acting at the interface of the immune and endocrine systems [88]. The effect of polymorphisms in MIF on pneumococcal disease were investigated in one phenotype study showing effect of the high expression allele (rs5844572) on developing the meningitis phenotype and one outcome study showing effect of high expression alleles (rs5844572, rs755622) on unfavourable outcome and death $[41,68]$. 


\section{Coagulation and fibrinolysis factors}

During severe infection the inflammatory response shifts the haemostatic balance towards a pro-coagulant state, which can lead to diffuse intravascular coagulation and organ damage [89]. Three studies assessed the effect of polymorphisms in coagulation or fibrinolysis genes on susceptibility and outcome of pneumococcal disease $[39,60,66]$. A study investigated the effect of the factor V Leiden (FVL) mutation (rs6025) in 163 patients and 8147 controls on IPD susceptibility and outcome, showing no significant associations [39].

Carboxypeptidase B2 (CPB2), also known as thrombin-activatable fibrinolysis inhibitor (TAFI), plays an anti-fibrinolytic role during fibrin clot degradation and an anti-inflammatory role by inactivating pro-inflammatory mediators, such as complement activation products [90]. A study with 716 pneumococcal meningitis patients studied the effect of polymorphisms in carboxypeptidase B2 (CPB2, rs1926447, rs3742264) on disease susceptibility and outcome [66]. No effect was found on susceptibility, but rs3742264 was associated with developing systemic complications (OR 0.40, 95\% CI 0.20-0.79) [66].

Plasminogen activator inhibitor 1 (PAI-1) inhibits the pro-fibrinolytic enzymes urokinase and tissue plasminogen activator and thereby modulates fibrinolysis [91]. The effect of rs1799889 in the gene coding for PAI-1 (SERPINE1) on pneumococcal meningitis outcome was studied in a Dutch study with 400 patients and they found an effect on occurrence of cerebral infarction (OR $2 \cdot 20$, 95\% CI 1.19-4.07), unfavourable outcome (OR $1.69,95 \%$ CI $1.03-2.78$ ) and mortality (OR $2 \cdot 20,95 \%$ CI $1 \cdot 02-4 \cdot 86)$ [60].

\section{Other factors}

Eight studies focused on genes that could not be categorized in the other subcategories. Two of these studies assessed the role of polymorphisms in the gene coding for C-reactive protein (CRP) in pneumococcal disease. $C R P$ contains a dinucleotide repeat polymorphism in the intron region ( $\mathrm{rs} 3138528)$ which was assessed in a study with 205 IPD patients and 345 controls, showing significantly more patients had the 134 base pair allele than controls (OR 1.52, 95\% CI 1.18-1.96) [20]. Another study investigated the effect of 3 polymorphisms in CRP (rs1800947, rs2794521, rs1130864) on outcome in 42 patients with a pneumococcal bacteraemia and found an association with mortality and rs2794521 (OR 9.6, 95\% CI 1.3-72.5), not corrected for multiple testing [28].

Protein thyrosine phosphatases (PTPs) regulate the immune response through influencing the responsiveness of $B$ and $T$ cell receptors [92]. Rs2476601in the gene coding for PTP non-receptor type 22 (PTPN22) was assessed in two studies with in total 1492 IPD patients and 2050 controls [25, 67]. The meta-analysis showed no effect on susceptibility [25].

Nitric oxide synthase 2 (NOS2) is an enzyme encoded by the NOS2 gene, which is involved in nitric oxide production and apoptosis of macrophages [93]. Nine polymorphisms in NOS2 were investigated in a Malawian study, showing no influence of any of the variants on IPD susceptibility or survival [36].

One study investigated if rs37972 in the glucocorticoidinduced transcript 1 gene (GLCCI1) influenced disease outcome and the response to glucocorticosteroids in pneumococcal meningitis [54]. The function of GLCCI1 unknown, but it is expressed in both lung cells and immune cells and may be an early marker of glucocorticoidinduced apoptosis [94]. No association was found between rs37972 and mortality rates per dexamethasone treatment group [54].

Studies have showed bacteria are able to hijack the $\beta 2$ adrenoceptor and thereby stabilize its binding to the endothelium which could enhance crossing the blood-brain barrier [95]. The effect of 2 functional polymorphisms in the $\beta 2$-adrenoceptor (ADRB2) gene on susceptibility and outcome of pneumococcal meningitis was studied in 396 patients and 376 controls [51]. Rs1042714 of ADRB2 was associated with susceptibility (OR 1.52, 95\% CI 1.12-2.07) but had no influence on outcome of disease [51].

\section{Studies with hypothesis free approach}

Five studies had a hypothesis free approach to find (new) genetic variations associated with pneumococcal disease. Two of them were sequencing studies in a selected group of genes [63, 72]. The first study sequenced 3 genes involved in the Toll-like receptor signalling pathway: MYD88, IRAK4, IKBKG (inhibitor of nuclear factor kappa-B kinase subunit gamma) of 164 IPD patients and 164 controls [63]. After sequencing 233 variants were identified of which one (rs4251545 in IRAK4) had a minor allele frequency (MAF) of more than $5 \%$. This variant was associated with susceptibility to IPD (OR 1.50; 95\% CI 1.10-2.04; $p=9.96 \times 10^{-3}$ ) but after correction for multiple testing this polymorphism did not retain statistical significance [63].

The other sequencing study sequenced 46 innate immune genes of 435 patients and 416 controls to assess the influence on outcome and susceptibility to pneumococcal meningitis [72]. They identified 2099 variations of which $80 \%$ had a MAF below $1 \%$ (1854 variations for susceptibility and 1385 for outcome). Neither the single nucleotide polymorphism (SNP) or haplotype analysis nor the analysis for association between a set of rare variants and phenotypes, reached the significance level after correction for multiple testing. The strongest associations with susceptibility were in CARD8, rs2008521 (OR 
1.82; CI $\left.1.28-2.75 ; p=8.2 \times 10^{-4}\right)$ and in CXCL1, rs56078309 (OR 1.96; CI 1.34-2.87; $p=8.2 \times 10^{-4}$ ) and with outcome were in IRAK4, rs4251552 (OR 2.86; CI $1.58-5.18 ; p=4.8 \times 10^{-4}$ ) and NOD2, rs2067085 (OR 2.16; CI 1.40-3.34; $p=5.1 \times 10^{-4}$ ) [72].

Two of the hypothesis free studies were exome wide association studies performed in the same Dutch cohort of pneumococcal meningitis patients $[69,71]$. Genotyping of subjects in these studies was done with an Illumina BeadChip consisting of more than 240,000 markers, with approximately $75 \%$ of these markers having a MAF below $5 \%$. The first study assessed susceptibility to pneumococcal meningitis and included 469 patients and 2072 controls and a total of 100,464 polymorphisms passed quality control thresholds [71]. The strongest associations with susceptibility were rs139064549 in COL11A1 (OR 3.21; 95\% CI 2.05-5.02; $\left.p=1.51 \times 10^{-6}\right)$ and rs9309464 in EXOC6B (OR 0.66; 95\% CI 0.54-0.81; $p=6.01 \times 10^{-5}$ ), both did not reach the exome wide significance level [71]. The study on outcome included 472 culture proven pneumococcal meningitis patients and their strongest association was in AKT3, rs10157763 (OR 1.88; 95\% CI 1.42.6; $p=9.9 \times 10^{-5}$ ) but this was not significant after correction for multiple testing [69].

The fifth hypothesis free study was a genome wide association study on pneumococcal bacteraemia susceptibility in 429 Kenyan children and 2677 controls [70]. In this study samples were genotyped with an Affymetrix ${ }^{\circ}$ SNP chip and polymorphisms not passing the quality control with a MAF of less than $1 \%$, a HWE of $p<1 \times$ $10^{-20}$ and a missingness of more than $2 \%$, were excluded for imputation. After sample and SNP quality control 787,861 genotyped autosomal SNPs were left for analysis, which were extended to 10,996,499 autosomal SNPs after imputation. The study identified an association which reached the genome wide significance threshold between rs140817150in a long intergenic noncoding RNA (lincRNA) gene (AC011288.2) and pneumococcal bacteraemia susceptibility and replicated the results in a replication cohort with 113 children and 1136 controls $(\mathrm{OR} 2.47,95 \%$ CI 1.84-3.31, $\mathrm{p}$-combined $=1.69 \times$ $\left.10^{-9}\right)[70]$.

\section{Discussion}

We identified 60 studies evaluating host genetic variations in 16,034 patients with pneumococcal disease. Meta-analyses showed that genetic variants in the genes CD14 (rs2569190) and MBL2 (one of the variant alleles rs1800450, rs1800451 or rs5030737) were associated with susceptibility to pneumococcal disease. A hypothesis free approach was applied in few studies resulting in one genome wide significant association in a gene coding for lincRNA (rs140817150) with IPD susceptibility which was replicated in an independent IPD cohort.
Few findings were replicated in independent cohorts. Replication generally led to negative results, or - in case of $M B L 2$ - careful analysis suggested considerable publication bias. The role of genetic variation on outcome was evaluated in about half of identified studies, but results were not confirmed because of the lack of detailed clinical metadata and heterogeneity of definitions and outcomes. To ease replication, international collaboration between study groups on genetics in pneumococcal disease is needed to ensure uniform research designs and outcome measures [96, 97]. This should lead to an open source research register for genetic associations studies, evaluating host and pathogen genetic data of pneumococcal disease, to facilitate data exchange and prevent publication bias. Such team-science effort is needed to decrease methodological flaws and contribute to more robust findings on the genetic basis of pneumococcal disease, a disease with enormous impact on global health $[1,97]$.

The significantly associated polymorphisms in the metaanalysis, in CD14 (rs2569190) and MBL2 (one of the variant alleles of rs1800450, rs1800451 or rs5030737) are known functional polymorphisms. The variant alleles of $M B L 2$ have structural differences which are associated with decreased MBL concentrations and thereby decreased activation of the complement system [98]. Soluble $\mathrm{CD} 14$ (sCD14) is a pattern recognition receptor and acts as a co-receptor of TLR- 4 to bind microbial components to endothelial and epithelial cells [99]. The risk allele $\mathrm{T}$ of rs2569190 for pneumococcal disease susceptibility in our meta-analysis, is associated with high sCD14 levels in expression studies $[100,101]$. Our findings correspond with other studies showing the $\mathrm{T}$ allele is associated with an increased occurrence of sepsis and increased serum SCD14 levels in patients with risk genotypes [102] [103]. Although the causal allele might be not the association signal due to linkage disequilibration, these studies are suggestive for a causal relationship of genetic variation in both $M B L 2$ or $C D 14$ and susceptibility to pneumococcal disease.

The results of our meta-analyses should be interpreted with caution because many included methodologically flawed studies. First of all, sample sizes were often inadequate, whereby robust conclusions on the influence of the studied genetic variants could not be drawn. In studies focusing on outcome, small sample sizes result in few unfavourable events per study group and consequentially limited study power. Second, in most studies data collection was retrospective which might have led to missing data. Many studies had a retrospective inclusion design which poses a risk for to selection bias as reflected by the extremely low mortality rates among included patients. In other studies DNA was not available for a considerable proportion of patients, particularly those with more 
severe disease passing away before DNA collection. Inclusion of patients with less severe disease decreases study power and could underestimate influence of polymorphisms on severity or mortality of pneumococcal disease. Third, case selection differed between studies. Different phenotypes of pneumococcal disease, ethnicities and age categories were studied which could possibly limit the meta-analysis. In 30\% of the studies ethnicity was mixed or not specified, which could be a major source for bias since frequencies of polymorphic genetic loci vary substantially between ethnic groups. Furthermore, control populations were heterogeneously selected and only 8 cohorts (of 57 cohorts; 14\%) matched for both age and sex. Fourth, quality control procedures for DNA extraction and genotyping were rarely specified. Only half of the studies which determined genotypes by PCR followed by allelic discrimination methods (21 of 41 studies) stated they confirmed genotypes by sequencing or retesting of samples. In the candidate gene studies only $15(27 \%)$ described the genotyping success rate and 7 (13\%) blinding of laboratory personal. Four out of the five hypothesis free studies described extensive quality control procedures like genotyping accuracy, calling rates, and rates of missing samples [69-72]. Finally, statistical analyses differed between studies leading to different effect sizes or different cut-offs for significant associations. Logistic regression with correction for confounders was done in only half of the studies and about one third of the studies that assessed three or more polymorphisms did not correct for multiple testing.

In recent years, many loci have been identified by GWAS, since the cost of genotyping SNPs decreased and the cohort sizes increased [104]. Despite the success in identifying disease loci, understanding of how polymorphisms predispose individuals to disease remains limited [104]. Besides methodological flaws, it is likely single genes or genetic variants do not control susceptibility and outcome of complex traits. Probably most heritability can be explained by effects on genes outside core pathways due to interconnection with genes in regulatory networks expressed in disease-relevant cells [105]. In order to understand the genetics of complex traits future studies should focus on gene-gene interactions as well [97]. Other future approaches for increasing our understanding in heritability could be targeted or whole-genome sequencing in people with extreme phenotypes, in order to find variants in the lower frequency with larger effect domains [97]. Besides reference panels of genomic variation should be adequately used to enhance coverage of existing and future GWAS and methods for detection of copy number variants and other structural variants could be improved [97]. Besides all this, functional understanding of these variants is needed for better insight in pathogenesis of disease and drug discovery. For example the whole genome association study of the Kenyan Bacteraemia Study Group explored the functionality of a polymorphism in a gene coding for lincRNA, with a qPCR to quantify levels of RNA expression in leukocyte cell subtypes, observing elevation only in neutrophils [70]. Most of the studies included in this review investigated a functional role of identified polymorphisms by measuring serum of CSF protein expression, [20, 26, 28, 34, 41, 42, 44, 47, 55, 56, 58, 60, 66, 69, 72] but not all were able to demonstrate a functional effect. Moreover the majority of the studies (70\%) did not analyse the functionality of the genetic variants.

\section{Conclusions}

Several host genetic polymorphisms have been identified to influence susceptibility and outcome of pneumococcal disease, but most of these studies are hampered by methodological flaws or were not reproduced (yet). Carefully designed whole-genome association and replication studies are needed with detailed clinical metadata to further clarify and confirm the genetic basis of pneumococcal disease. To improve our understanding in the functionality of polymorphisms the next step is to investigate the downstream molecular effects of polymorphisms with large-scale clinical cohort studies within a specific acute illness as pneumococcal disease.

\section{Additional files}

Additional file 1: Table S1. Synonyms of genetic variants (DOCX $13 \mathrm{~kb}$ )

Additional file 2: Meta-analyses of genetic association studies on susceptibility and outcome of pneumococcal disease. (PDF 505 kb)

\section{Abbreviations \\ AA: African Americans; ADRB2: $\beta 2$-adrenoceptor; CAP: Community acquired pneumococcal pneumonia; CPB2: Carboxypeptidase B2; CRP: C-reactive protein; EA: European Americans; Fc: Fragment crystallizable; FVL: Factor V Leiden; GLCCI1: Glucocorticoid-induced transcript 1 gene; Ig: Immunoglobulin; IKBKG: Inhibitor of nuclear factor kappa-B kinase subunit gamma; IL: Interleukin; IPD: Invasive pneumococcal disease; lincRNA: Long intergenic non-coding RNA; MAF: Minor allele frequency; MASP: MBL- associated serine protease; MBL: Mannose-binding lectin; MIF: Macrophage migrating inhibitory factor; NFkB: Nuclear factor kappa-light-chain-enhancer of activated B cells; NLR: Nod-like receptor; NOS2: Nitric oxide synthase 2; PAl-1: Plasminogen activator inhibitor 1; PCR: Polymerase chain reaction; PTP: Protein thyrosine phosphatase; SFTPA: Surfactant protein A; SFTPD: Surfactant protein D; SNP: Single nucleotide polymorphism; TAFI: Thrombin-activatable fibrinolysis inhibitor; TIRAP: Toll interleukin-1 receptor domain-containing adaptor protein; TLR: Toll-like receptor; TNF: Tumor necrosis factor}

\section{Acknowledgements}

Not applicable.

\section{Authors' contributions}

AK performed the search, study selection, data extraction and statistical analyses, and wrote the first draft of the manuscript. MB and DB conceived the study, provided funding and study supervision, and revised the final manuscript. All authors read and approved the final manuscript. 


\section{Funding}

This study was supported by the Netherlands Organization for Health Research and Development (ZonMw; NWO-Vidi-Grant [917.17.308] to MB, NWO-Vidi-Grant [016.116.358] to DB) and the European Research Council (ERC Starting Grant to DB). The funding bodies had no role in the design of the study and collection, analysis, and interpretation of data and in writing the manuscript.

\section{Availability of data and materials}

The datasets used and/or analysed during the current study are available from the corresponding author on reasonable request.

\section{Ethics approval and consent to participate}

Not applicable.

\section{Consent for publication}

Not applicable.

\section{Competing interests}

The authors declare that they have no competing interests.

\section{Received: 4 April 2019 Accepted: 16 August 2019} Published online: 13 September 2019

\section{References}

1. Mortality GBD. Causes of death C. global, regional, and national life expectancy, all-cause mortality, and cause-specific mortality for 249 causes of death, 1980-2015: a systematic analysis for the global burden of disease Study 2015. Lancet. 2016;388(10053):1459-544.

2. Welte T, Torres A, Nathwani D. Clinical and economic burden of community-acquired pneumonia among adults in Europe. Thorax. 2012; 67(1):71-9.

3. Drijkoningen JJ, Rohde GG. Pneumococcal infection in adults: burden of disease. Clin Microbiol Infect. 2014;20(Suppl 5):45-51.

4. Niederman MS. Community-acquired pneumonia: the U.S. perspective. Semin Respir Crit Care Med. 2009:30(2):179-88.

5. Wahl B, O'Brien KL, Greenbaum A, Majumder A, Liu L, Chu Y, et al. Burden of Streptococcus pneumoniae and Haemophilus influenzae type b disease in children in the era of conjugate vaccines: global, regional, and national estimates for 2000-15. Lancet Glob Health. 2018;6(7):e744-e57.

6. Marrie TJ, Tyrrell GJ, Majumdar SR, Eurich DT. Effect of Age on the Manifestations and Outcomes of Invasive Pneumococcal Disease in Adults. Am J Med. 2018;131(1):100 e1-7.

7. van de Beek D, Brouwer M, Hasbun R, Koedel U, Whitney CG, Wijdicks E. Community-acquired bacterial meningitis. Nat Rev Dis Primers. 2016;2: 16074.

8. Lynch JP 3rd, Zhanel GG. Streptococcus pneumoniae: epidemiology, risk factors, and strategies for prevention. Semin Respir Crit Care Med. 2009; 30(2):189-209.

9. Bijlsma MW, Brouwer MC, Kasanmoentalib ES, Kloek AT, Lucas MJ, Tanck MW, et al. Community-acquired bacterial meningitis in adults in the Netherlands, 2006-14: a prospective cohort study. Lancet Infect Dis. 2016;16: 339-47.

10. LeBlanc JJ, ElSherif M, Ye L, MacKinnon-Cameron D, Li L, Ambrose A, et al. Burden of vaccine-preventable pneumococcal disease in hospitalized adults: a Canadian immunization research network (CIRN) serious outcomes surveillance (SOS) network study. Vaccine. 2017;35(29):3647-54.

11. Thomas K, Mukkai Kesavan L, Veeraraghavan B, Jasmine S, Jude J, Shubankar $M$, et al. Invasive pneumococcal disease associated with high case fatality in India. J Clin Epidemiol. 2013;66(1):36-43.

12. Robinson KA, Baughman W, Rothrock G, Barrett NL, Pass M, Lexau C, et al. Epidemiology of invasive Streptococcus pneumoniae infections in the United States, 1995-1998: opportunities for prevention in the conjugate vaccine era. JAMA. 2001;285(13):1729-35.

13. Brouwer MC, de Gans J, Heckenberg SG, Zwinderman AH, van der Poll T, van de Beek D. Host genetic susceptibility to pneumococcal and meningococcal disease: a systematic review and meta-analysis. Lancet InfectDis. 2009;9(1):31-44.

14. Chapman SJ, Hill AV. Human genetic susceptibility to infectious disease. NatRevGenet. 2012;13(3):175-88.
15. Ludwig E, Bonanni P, Rohde G, Sayiner A, Torres A. The remaining challenges of pneumococcal disease in adults. Eur Respir Rev. 2012; 21(123):57-65.

16. Review Manager (RevMan) Version 5.3 ed. Copenhagen: The Nordic Cochrane Centre, The Cochrane Collaboration; 2014.

17. Yee AM, Phan HM, Zuniga R, Salmon JE, Musher DM. Association between FcgammaRlla-R131 allotype and bacteremic pneumococcal pneumonia. Clin Infect Dis. 2000;30(1):25-8.

18. Kronborg G, Weis N, Madsen HO, Pedersen SS, Wejse C, Nielsen H, et al. Variant mannose-binding lectin alleles are not associated with susceptibility to or outcome of invasive pneumococcal infection in randomly included patients. J Infect Dis. 2002;185(10):1517-20.

19. Roy S, Knox K, Segal S, Griffiths D, Moore CE, Welsh Kl, et al. MBL genotype and risk of invasive pneumococcal disease: a case-control study. Lancet. 2002:359(9317):1569-73.

20. Roy S, Hill AV, Knox K, Griffiths D, Crook D. Research pointers: association of common genetic variant with susceptibility to invasive pneumococcal disease. BMJ. 2002;324(7350):1369.

21. Schaaf BM, Boehmke F, Esnaashari $H$, Seitzer $U$, Kothe $H$, Maass M, et al. Pneumococcal septic shock is associated with the interleukin-10-1082 gene promoter polymorphism. Am J Respir Crit Care Med. 2003;168(4):476-80.

22. Yuan FF, Wong M, Pererva N, Keating J, Davis AR, Bryant JA, et al. FcgammaRIIA polymorphisms in Streptococcus pneumoniae infection. Immunol Cell Biol. 2003;81(3):192-5.

23. Schaaf B, Rupp J, Muller-Steinhardt M, Kruse J, Boehmke F, Maass M, et al. The interleukin-6 -174 promoter polymorphism is associated with extrapulmonary bacterial dissemination in Streptococcus pneumoniae infection. Cytokine. 2005;31(4):324-8.

24. Moens L, Van Hoeyveld E, Verhaegen J, De Boeck K, Peetermans WE, Bossuyt X. Fcgamma-receptor IIA genotype and invasive pneumococcal infection. Clin Immunol. 2006;118(1):20-3.

25. Chapman SJ, Khor CC, Vannberg FO, Maskell NA, Davies CW, Hedley EL, et al. PTPN22 and invasive bacterial disease. Nat Genet. 2006;38(5):499-500.

26. Perez-Castellano M, Penaranda M, Payeras A, Mila J, Riera M, Vidal J, et al. Mannose-binding lectin does not act as an acute-phase reactant in adults with community-acquired pneumococcal pneumonia. Clin Exp Immunol. 2006;145(2):228-34.

27. Moens L, Van Hoeyveld E, Peetermans WE, De Boeck C, Verhaegen J, Bossuyt X. Mannose-binding lectin genotype and invasive pneumococcal infection. Hum Immunol. 2006;67(8):605-11.

28. Eklund C, Huttunen R, Syrjanen J, Laine J, Vuento R, Hurme M. Polymorphism of the C-reactive protein gene is associated with mortality in bacteraemia. Scand J Infect Dis. 2006:38(11-12):1069-73.

29. Khor CC, Chapman SJ, Vannberg FO, Dunne A, Murphy C, Ling EY, et al. A mal functional variant is associated with protection against invasive pneumococcal disease, bacteremia, malaria and tuberculosis. Nat Genet. 2007:39(4):523-8

30. Moens L, Verhaegen J, Pierik M, Vermeire S, De Boeck K, Peetermans WE, et al. Toll-like receptor 2 and toll-like receptor 4 polymorphisms in invasive pneumococcal disease. Microbes Infect. 2007;9(1):15-20.

31. Chapman SJ, Vannberg FO, Khor CC, Segal S, Moore CE, Knox K, et al. Functional polymorphisms in the FCN2 gene are not associated with invasive pneumococcal disease. Mol Immunol. 2007:44(12):3267-70.

32. Chapman SJ, Khor CC, Vannberg FO, Frodsham A, Walley A, Maskell NA, et al. IkappaB genetic polymorphisms and invasive pneumococcal disease. Am J Respir Crit Care Med. 2007;176(2):181-7.

33. Yuan FF, Marks K, Wong M, Watson S, de Leon E, Mclntyre PB, et al. Clinical relevance of TLR2, TLR4, CD14 and FcgammaRIIA gene polymorphisms in Streptococcus pneumoniae infection. Immunol Cell Biol. 2008;86(3):268-70.

34. Garcia-Laorden MI, Sole-Violan J, Rodriguez de Castro F, Aspa J, Briones ML, Garcia-Saavedra A, et al. Mannose-binding lectin and mannose-binding lectin-associated serine protease 2 in susceptibility, severity, and outcome of pneumonia in adults. J Allergy Clin Immunol. 2008;122(2):368-74-74 e1-2.

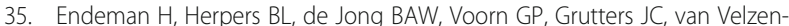
Blad $\mathrm{H}$, et al. Mannose-binding lectin genotypes in susceptibility to community-acquired pneumonia. Chest. 2008;134(6):1135-40.

36. Payton A, Payne D, Mankhambo LA, Banda DL, Hart CA, Ollier WE, et al. Nitric oxide synthase 2A (NOS2A) polymorphisms are not associated with invasive pneumococcal disease. BMC Med Genet. 2009;10:28.

37. Endeman H, Cornips MC, Grutters JC, van den Bosch JM, Ruven HJ, van Velzen-Blad H, et al. The Fcgamma receptor IIA-R/R131 genotype is 
associated with severe sepsis in community-acquired pneumonia. Clin Vaccine Immunol. 2009;16(7):1087-90.

38. Chapman SJ, Khor CC, Vannberg FO, Rautanen A, Segal S, Moore CE, et al. NFKBIZ polymorphisms and susceptibility to pneumococcal disease in European and African populations. Genes Immun. 2010;11(4):319-25.

39. Benfield T, Ejrnaes K, Juul K, Ostergaard C, Helweg-Larsen J, Weis N, et al. Influence of factor $V$ Leiden on susceptibility to and outcome from critical illness: a genetic association study. Crit Care. 2010;14(2):R28.

40. Chapman SJ, Khor CC, Vannberg FO, Rautanen A, Walley A, Segal S, et al. Common NFKBIL2 polymorphisms and susceptibility to pneumococcal disease: a genetic association study. Crit Care. 2010;14(6):R227.

41. Doernberg S, Schaaf B, Dalhoff K, Leng L, Beitin A, Quagliarello V, et al. Association of macrophage migration inhibitory factor (MIF) polymorphisms with risk of meningitis from Streptococcus pneumoniae. Cytokine. 2011; 53(3):292-4

42. Carrol ED, Payton A, Payne D, Miyajima F, Chaponda M, Mankhambo LA, et al. The IL1RN promoter rs4251961 correlates with IL-1 receptor antagonist concentrations in human infection and is differentially regulated by GATA-1. J Immunol. 2011;186(4):2329-35.

43. Sanders MS, van Well GT, Ouburg S, Lundberg PS, van Furth AM, Morre SA. Single nucleotide polymorphisms in TLR9 are highly associated with susceptibility to bacterial meningitis in children. Clin Infect Dis. 2011;52(4): 475-80.

44. Garcia-Laorden MI, Rodriguez de Castro F, Sole-Violan J, Rajas O, Blanquer J, Borderias $L$, et al. Influence of genetic variability at the surfactant proteins $A$ and D in community-acquired pneumonia: a prospective, observational, genetic study. Crit Care. 2011;15(1):R57.

45. Sole-Violan J, Garcia-Laorden MI, Marcos-Ramos JA, de Castro FR, Rajas O, Borderias $L$, et al. The Fcgamma receptor $\| \mathrm{A}-\mathrm{H} / \mathrm{H} 131$ genotype is associated with bacteremia in pneumococcal community-acquired pneumonia. Crit Care Med. 2011;39(6):1388-93.

46. Lingappa JR, Dumitrescu L, Zimmer SM, Lynfield R, McNicholl JM, Messonnier NE, et al. Identifying host genetic risk factors in the context of public health surveillance for invasive pneumococcal disease. PLoS One. 2011;6(8):e23413.

47. Woehrl B, Brouwer MC, Murr C, Heckenberg SG, Baas F, Pfister HW, et al. Complement component 5 contributes to poor disease outcome in humans and mice with pneumococcal meningitis. JClinInvest. 2011;121(10): 3943-53.

48. Martin-Loeches I, Sole-Violan J. Rodriguez de Castro F, Garcia-Laorden MI, Borderias $L$, Blanquer J, et al. variants at the promoter of the interleukin- 6 gene are associated with severity and outcome of pneumococcal community-acquired pneumonia. Intensive Care Med. 2012;38(2):256-62.

49. Garcia-Laorden MI. Rodriguez de Castro F, Sole-Violan J, Payeras a, Briones $M L$, Borderias $L$, et al. the role of mannose-binding lectin in pneumococcal infection. Eur Respir J. 2013;41(1):131-9.

50. Garnacho-Montero J, Garcia-Cabrera E, Jimenez-Alvarez R, Diaz-Martin A, Revuelto-Rey J, Aznar-Martin J, et al. Genetic variants of the MBL2 gene are associated with mortality in pneumococcal sepsis. Diagn Microbiol Infect Dis. 2012;73(1):39-44.

51. Adriani KS, Brouwer MC, Baas F, Zwinderman AH, van der Ende A, van de Beek D. Genetic variation in the beta2-Adrenocepter gene is associated with susceptibility to bacterial meningitis in adults. PLoSOne. 2012;7(5): e37618.

52. Bougle A, Max A, Mongardon N, Grimaldi D, Pene F, Rousseau C, et al. Protective effects of FCGR2A polymorphism in invasive pneumococcal diseases. Chest. 2012;142(6):1474-81.

53. van Well GT, Sanders MS, Ouburg $S$, van Furth AM, Morre SA Polymorphisms in toll-like receptors 2, 4, and 9 are highly associated with hearing loss in survivors of bacterial meningitis. PLoS One. 2012;7(5):e35837.

54. Brouwer MC, van der Ende A, Baas F, van de Beek D. Genetic variation in GLCCI1 and dexamethasone in bacterial meningitis. J Infect. 2012; 65(5):465-7.

55. Geldhoff M, Mook-Kanamori BB, Brouwer MC, Valls SM, Baas F, van der Ende $A$, et al. Genetic variation in inflammasome genes is associated with outcome in bacterial meningitis. Immunogenetics. 2013;65(1):9-16.

56. Adriani KS, Brouwer MC, Geldhoff M, Baas F, Zwinderman AH, Paul Morgan $B$, et al. Common polymorphisms in the complement system and susceptiblity to bacterial meningitis. J Infect. 2013;66(3):255-62.

57. van Well GT, Sanders MS, Ouburg S, Kumar V, van Furth AM, Morre SA. Single nucleotide polymorphisms in pathogen recognition receptor genes are associated with susceptibility to meningococcal meningitis in a pediatric cohort. PLoS One. 2013;8(5):e64252.

58. Brouwer MC, Baas F, van der Ende A, van de Beek D. Genetic variation and cerebrospinal fluid levels of mannose binding lectin in pneumococcal meningitis patients. PLoS One. 2013;8(5):e65151.

59. Telleria-Orriols JJ, Garcia-Salido A, Varillas D, Serrano-Gonzalez A, CasadoFlores J. TLR2-TLR4/CD14 polymorphisms and predisposition to severe invasive infections by Neisseria meningitidis and Streptococcus pneumoniae. Med Int. 2014;38(6):356-62.

60. Brouwer MC, Meijers JC, Baas F, van der Ende A, Pfister HW, Giese A, et al. Plasminogen activator inhibitor-1 influences cerebrovascular complications and death in pneumococcal meningitis. Acta Neuropathol. 2014;127(4):553-64.

61. Munoz-Almagro C, Bautista C, Arias MT, Boixeda R, Del Amo E, Borras C, et al. High prevalence of genetically-determined mannose binding lectin deficiency in young children with invasive pneumococcal disease. Clin Microbiol Infect. 2014;20(10):0745-52.

62. Lundbo LF, Harboe ZB, Clausen LN, Hollegaard MV, Sorensen HT, Hougaard DM, et al. Mannose-binding lectin gene, MBL2, polymorphisms are not associated with susceptibility to invasive pneumococcal disease in children. Clin Infect Dis. 2014;59(4):e66-71.

63. Ellis MK, Elliott KS, Rautanen A, Crook DW, Hill AV, Chapman SJ. Rare variants in MYD88, IRAK4 and IKBKG and susceptibility to invasive pneumococcal disease: a population-based case-control study. PLoS One. 2015;10(4): e0123532.

64. Mills TC, Chapman S, Hutton P, Gordon AC, Bion J, Chiche JD, et al. Variants in the mannose-binding lectin gene MBL2 do not associate with Sepsis susceptibility or survival in a large European cohort. Clin Infect Dis. 2015;61(5):695-703.

65. Carrasco-Colom J, Jordan I, Alsina L, Garcia-Garcia JJ, Cambra-Lasaosa FJ, Martin-Mateos MA, et al. Association of Polymorphisms in IRAK1, IRAK4 and MyD88, and severe invasive pneumococcal disease. Pediatr Infect Dis J. 2015;34(9):1008-13.

66. Mook-Kanamori BB, Valls Seron M, Geldhoff M, Havik SR, van der Ende A, Baas F, et al. Thrombin-activatable fibrinolysis inhibitor influences disease severity in humans and mice with pneumococcal meningitis. J Thromb Haemost. 2015;13(11):2076-86.

67. Lundbo LF, Harboe ZB, Clausen LN, Hollegaard MV, Sorensen HT, Hougaard DM, et al. Genetic variation in NFKBIE is associated with increased risk of pneumococcal meningitis in children. EBioMedicine. 2016;3:93-9.

68. Savva A, Brouwer MC, Roger T, Valls Seron M, Le Roy D, Ferwerda B, et al. Functional polymorphisms of macrophage migration inhibitory factor as predictors of morbidity and mortality of pneumococcal meningitis. Proc Natl Acad Sci U S A. 2016;113(13):3597-602

69. Valls Seron M, Ferwerda B, Engelen-Lee J, Geldhoff M, Jaspers V, Zwinderman $\mathrm{AH}$, et al. V-AKT murine thymoma viral oncogene homolog 3 (AKT3) contributes to poor disease outcome in humans and mice with pneumococcal meningitis. Acta Neuropathol Commun. 2016;4(1):50.

70. Kenyan Bacteraemia Study G, Wellcome Trust Case Control C, Rautanen A, Pirinen M, Mills TC, Rockett KA, et al. Polymorphism in a lincRNA associates with a doubled risk of pneumococcal bacteremia in Kenyan children. Am J Hum Genet. 2016:98(6):1092-100.

71. Kloek AT, van Setten J, van der Ende A, Bots ML, Asselbergs FW, Valls Seron $M$, et al. Exome Array analysis of susceptibility to pneumococcal meningitis. Sci Rep. 2016;6:29351.

72. Ferwerda B, Valls Seron M, Jongejan A, Zwinderman AH, Geldhoff M, van der Ende $A$, et al. Variation of 46 innate immune genes evaluated for their contribution in pneumococcal meningitis susceptibility and outcome. EBioMedicine. 2016;10:77-84.

73. Kasanmoentalib ES, Valls Seron M, Ferwerda B, Tanck MW, Zwinderman AH, Baas F, et al. Mannose-binding lectin-associated serine protease 2 (MASP-2) contributes to poor disease outcome in humans and mice with pneumococcal meningitis. J Neuroinflammation. 2017;14(1):2.

74. Gowin E, Swiatek-Koscielna B, Kaluzna E, Nowak J, Michalak M, Wysocki J, et al. Analysis of TLR2, TLR4, and TLR9 single nucleotide polymorphisms in children with bacterial meningitis and their healthy family members. Int J Infect Dis. 2017:60:23-8.

75. Sangil A, Arranz MJ, Guerri-Fernandez R, Perez M, Monzon H, Payeras A, et al. Genetic susceptibility to invasive pneumococcal disease. Infect Genet Evol. 2018;59:126-31.

76. Gowin E, Swiatek-Koscielna B, Kaluzna E, Strauss E, Wysocki J, Nowak J, et al. How many single-nucleotide polymorphisms (SNPS) must be tested in order 
to prove susceptibility to bacterial meningitis in children? Analysis of 11 SNPs in seven genes involved in the immune response and their effect on the susceptibility to bacterial meningitis in children. Innate Immun. 2018; 24(3):163-70.

77. Kumar H, Kawai T, Akira S. Pathogen recognition by the innate immune system. Int Rev Immunol. 2011;30(1):16-34.

78. Garred P, Genster N, Pilely K, Bayarri-Olmos R, Rosbjerg A, Ma YJ, et al. A journey through the lectin pathway of complement-MBL and beyond. Immunol Rev. 2016;274(1):74-97.

79. Matsushita M, Endo Y, Fujita T. Structural and functional overview of the lectin complement pathway: its molecular basis and physiological implication. Arch Immunol Ther Exp. 2013;61(4):273-83.

80. Ujma S, Horsnell WG, Katz AA, Clark HW, Schafer G. Non-pulmonary immune functions of surfactant proteins a and D. J Innate Immun. 2017;9(1):3-11.

81. Endo Y, Matsushita M, Fujita T. New insights into the role of ficolins in the lectin pathway of innate immunity. Int Rev Cell Mol Biol. 2015;316:49-110.

82. Yan C, Gao H. New insights for $\mathrm{C} 5 \mathrm{a}$ and $\mathrm{C} 5 \mathrm{a}$ receptors in sepsis. Front Immunol. 2012;3:368.

83. Pincetic A, Bournazos S, DiLillo DJ, Maamary J, Wang TT, Dahan R, et al. Type I and type $\| \mathrm{fc}$ receptors regulate innate and adaptive immunity. Nat Immunol. 2014;15(8):707-16.

84. Hargreaves CE, Rose-Zerilli MJ, Machado LR, Iriyama C, Hollox EJ, Cragg MS, et al. Fcgamma receptors: genetic variation, function, and disease. Immunol Rev. 2015;268(1):6-24.

85. Hayden MS, West AP, Ghosh S. NF-kappaB and the immune response. Oncogene. 2006;25(51):6758-80.

86. Faix JD. Biomarkers of sepsis. Crit Rev Clin Lab Sci. 2013:50(1):23-36.

87. Hanada T, Yoshimura A. Regulation of cytokine signaling and inflammation. Cytokine Growth Factor Rev. 2002;13(4-5):413-21.

88. Calandra T. Macrophage migration inhibitory factor and host innate immune responses to microbes. Scand J Infect Dis. 2003;35(9):573-6.

89. Levi M, Poll T. Coagulation in patients with severe sepsis. Semin Thromb Hemost. 2015;41(1):9-15.

90. Campbell WD, Lazoura E, Okada N, Okada H. Inactivation of C3a and C5a octapeptides by carboxypeptidase $\mathrm{R}$ and carboxypeptidase $\mathrm{N}$. Microbiollmmunol. 2002;46(2):131-4.

91. Iwaki T, Urano T, Umemura K. PAl-1, progress in understanding the clinical problem and its aetiology. BrJHaematol. 2012;157(3):291-8.

92. Stanford SM, Rapini N, Bottini N. Regulation of TCR signalling by tyrosine phosphatases: from immune homeostasis to autoimmunity. Immunology. 2012;137(1):1-19.

93. Marriott HM, Ali F, Read RC, Mitchell TJ, Whyte MK, Dockrell DH. Nitric oxide levels regulate macrophage commitment to apoptosis or necrosis during pneumococcal infection. FASEB J. 2004;18(10):1126-8.

94. Tantisira KG, Lasky-Su J, Harada M, Murphy A, Litonjua AA, Himes BE, et al. Genomewide association between GLCCl1 and response to glucocorticoid therapy in asthma. N Engl J Med. 2011;365(13):1173-83.

95. Coureuil M, Lecuyer H, Scott MG, Boularan C, Enslen H, Soyer M, et al. Meningococcus hijacks a beta2-adrenoceptor/beta-Arrestin pathway to cross brain microvasculature endothelium. Cell. 2010;143(7):1149-60.

96. van de Beek D. Progress and challenges in bacterial meningitis. Lancet. 2012;380(9854):1623-4

97. Manolio TA, Collins FS, Cox NJ, Goldstein DB, Hindorff LA, Hunter DJ, et al. Finding the missing heritability of complex diseases. Nature. 2009; 461(7265):747-53

98. Turner MW, Hamvas RM. Mannose-binding lectin: structure, function, genetics and disease associations. Rev Immunogenet. 2000;2(3):305-22.

99. Landmann R, Reber AM, Sansano S, Zimmerli W. Function of soluble CD14 in serum from patients with septic shock. J Infect Dis. 1996:173(3):661-8.

100. Nieto-Fontarigo JJ, Salgado FJ, San-Jose ME, Cruz MJ, Casas-Fernandez A, Gomez-Conde MJ, et al. The CD14 (-159 C/T) SNP is associated with SCD14 levels and allergic asthma, but not with CD14 expression on monocytes. Sci Rep. 2018;8(1):4147.

101. Keskin O, Birben E, Sackesen C, Soyer OU, Alyamac E, Karaaslan C, et al. The effect of CD14-c159T genotypes on the cytokine response to endotoxin by peripheral blood mononuclear cells from asthmatic children. Ann Allergy Asthma Immunol. 2006:97(3):321-8.

102. Fan WC, Liu CW, Ou SM, Huang CC, Li TH, Lee KC, et al. TLR4/CD14 variantsrelated serologic and immunologic Dys-regulations predict severe Sepsis in febrile De-compensated cirrhotic patients. PLoS One. 2016;11(11):e0166458.
103. Wu Q, Xu X, Ren J, Liu S, Liao X, Wu X, et al. Association between the $-159 C / T$ polymorphism in the promoter region of the CD14 gene and sepsis: a meta-analysis. BMC Anesthesiol. 2017;17(1):11.

104. Wijmenga C, Zhernakova A. The importance of cohort studies in the postGWAS era. Nat Genet. 2018;50(3):322-8.

105. Boyle EA, Li Yl, Pritchard JK. An expanded view of complex traits: from polygenic to Omnigenic. Cell. 2017;169(7):1177-86.

\section{Publisher's Note}

Springer Nature remains neutral with regard to jurisdictional claims in published maps and institutional affiliations.
Ready to submit your research? Choose BMC and benefit from:

- fast, convenient online submission

- thorough peer review by experienced researchers in your field

- rapid publication on acceptance

- support for research data, including large and complex data types

- gold Open Access which fosters wider collaboration and increased citations

- maximum visibility for your research: over $100 \mathrm{M}$ website views per year

At $\mathrm{BMC}$, research is always in progress.

Learn more biomedcentral.com/submissions 